UNIVERSIDADE DE SÃo PAULO

Faculdade de Medicina de Ribeirão Preto

\title{
ESTUDO DAS ASSOCIAÇÕES CLÍNICA, LABORATORIAL E RADIOGRÁFICA NA COLUNA \\ CERVICAL DE PACIENTES COM ARTRITE REUMATÓIDE
}

\section{6}

BIBLIOTECA

FACULDADE DE MEDICINA DE

RIBEIRAO PRFTO DA U.S.P.
Tese apresentada ao Departamento de Biomecânica, Medicina e Reabilitação do Aparelho Locomotor da Faculdade de Medicina de Ribeirão Preto - USP, para obtenção do Título de Doutor em Medicina
Aluno: Cesar Prado de Souza
Orientador: Prof. Dr. Helton L.A. Defino

Ribeirão Preto - 2000 


\section{Souza, Cesar Prado}

Estudo das associaçōes clínica, laboratorial e radiográfica na coluna cervical de pacientes com artrite reumatóide, 2000.

94 p.: il.; $29,7 \mathrm{~cm}$.

Tese (Doutorado - Curso de Pós-Graduação em Ortopedia e Traumatologia) --Faculdade de Medicina de Ribeirão Preto - Universidade de São Paulo.

1. Artrite reumatóide; 2 . Coluna Cervical; 3 . Instabilidade 


\section{DEDICATÓRIA}

\section{A Deus,}

pela maravilhosa atuação misteriosa e capacitação na arte médica. A Ele rendo graças.

Não te mandei eu? Sê forte e corajoso; não temas, nem te espantes, por que o Senhor teu Deus é contigo, por onde quer que andares. (Joel 1:9) 
Aos meus pais, Aloisio e Zenite e minha irmã Eliana, pelo carinho, amor e pelos estímulos recebidos que muito contribuíram para a minha formação.

\section{À minha esposa Larissa,}

pelo amor, dedicação e compreensão

À lara,

a filha que nasce. 


\section{AGRADECIMENTOS}

\section{Ao Prof. Dr. Helton L.A. Defino,}

orientador exemplar e responsável por este trabalho, oferencendo-me incansável colaboração que muito contribuiu ao aperfeiçoamento da minha formação médica.

Dá instrução ao sábio e ele se fará mais sábio ainda. (Prov 9:9) 


\section{AGRADECIMENTOS}

Ao Prof. Dr. José B. Volpon, pelos ensinamentos e colaboração neste período de formação.

Ao Prof. Dr. Cláudio H. Barbieri, pela colaboração neste trabalho.

A todos os Professores da Área de Ortopedia da FMRP-USP, pelos ensinamentos e acolhida.

Aos Profs. Drs. Eduardo A. Donadi, Julio C. Voltarelli e Flávio C. Petean da Disciplina de Imunologia Clínica, pela valiosa contribuição na realização deste trabalho junto ao Ambulatório de Imunologia Clínica.

Aos Colegas Ortopedistas, Dr. Alcides Durigan Jr., Dr. Roberto R. Mizobuchi, Dr. Décio Cerqueira de Moraes Filho, Dr. João Carlos D. Ferreira, Dr. Lélio C. Batista e secretária Anísia Mansueti, pelo companheirismo e estímulo no início deste trabalho.

Aos Colegas Ortopedistas, Dr. Paulo Custódio, Dr. Nilo Taninaka, Dr. Luis Alberto M. de Souza, Dr. José Milton Pellozzo, Dr. Mauricio A. Allet, Dr. José L. Ribeiro e Dr. Paulo Marcio E. Fonseca, pela ajuda e compreensão nas minhas ausências.

Ao Geraldo Cassio dos Reis, estatístico do Departamento de Neurologia da FMRP-USP, pelo valioso auxílio e orientação nos serviços estatísticos.

À Laucéa Conrado da Silva, pela incansável dedicação durante todo este trabalho, na realização de digitação, formatação $e$ análise dos dados.

Ao Sr. André Luis M. Matos, do Centro de Imagem e Física Médica do Departamento de Radiologia da FMRP-USP, pelos serviços de computação gráfica na confecção das imagens radiográficas.

A Sra. Marlene Lúcio, pela colaboração na digitação $\Theta$ correção gramatical deste trabalho. 
Às secretárias da Área de Ortopedia e Traumatologia da FMRP-USP: Maria de Fatima Feitosa Lima, Rosa Pereira Brites Alves e Elizangela Bernardes de Oliveira, pela atenção como nos receberam.

Às funcionárias da Casa de Hóspedes do Campus de Ribeirão PretoUSP: Cleusa Maria A. de Souza, Shirlene Marciano Ingisa, Lúcia de Lourdes F. Tavares, Ana Lúcia Apolinário e Rita de Cássia D. Saraiva, pela acolhida calorosa durante os períodos da realização deste trabalho.

A todos aqueles que contribuíram, direta ou indiretamente, para a realização deste trabalho. 


\section{SUMÁRIO}

Dedicatória

Agradecimentos

Resumo

1. INTRODUÇÃO

1.1. Fisiopatologia..................................................................... 02

1.2. Evolução Clínica................................................................... 08

1.3. Objetivo do Trabalho..................................................... 09

2. CASUÍSTICA E MÉTODO ..................................................... 11

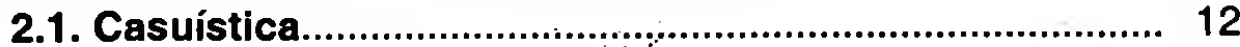

2.1.1. Critério de Inclusão................................................... 12

2.1.2. Critério de Exclusão ....:............................................. 12

2.2. Método.......................................................................... 13

2.2.1. Métodos de Avaliação............................................... 13

2.2.1.1. Avaliaçãơ clínica......................................... 13

2.2.1.2. Critério diagnóstico de artrite reumatóide..... 14

2.2.1.3. Classificação da Capacidade Funcional do American College of Rheumatology (ACR).. 15

2.2.1.4. Classificação em estágios da artrite reumatóide segundo a American

Rheumatism Association (ARA)................... 16

2.2.1.5. Avaliação laboratorial................................... 17

2.2.1.6. Avaliação radiográfica................................... 17

2.2.1.6.1. Método de Ranawat.................... 18

2.2.1.6.2. Método de Redlund-Johnell \& Pettersson.................................... 18

2.2.1.6.3. Método de MacGregor................. 19

2.2.1.6.4. Subluxação atlanto-axial $\left(C_{1}-C_{2}\right) . \quad 19$

2.2.1.6.5. Subluxação subaxial e múltipla

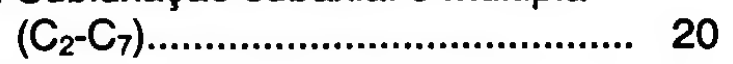

2.2.1.6.6. Alteraçōes degenerativas............. 22

2.2.1.7. Estudo das associações entre as variáveis estudadas...................................... 23

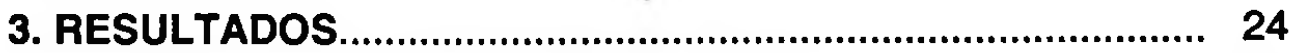

3.1. Avaliação Clínica........................................................... 25

3.2. Avaliação Laboratorial.................................................. 27

3.3. Avaliação Clínica Segundo os Critérios da ACR............. 28

3.4. Classificação em Estágios da Artrite Reumatóide (AR) segundo a ARA ............................................................. 29

3.5. Classificação da Capacidade Funcional ........................ 30

3.6. Avaliação Radiográfica................................................ 30

3.6.1. Método de Ranawat.................................................. 32

3.6.2. Método de Redlund-Johnell.\& Pettersson.................. 33 


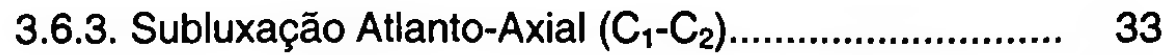

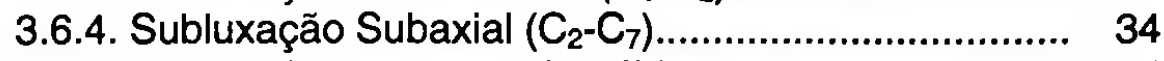

3.6.5. Erosão do processo adontóide................................. 34

3.6.6. Fusão óssea........................................................... 35

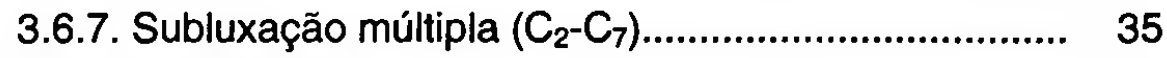

3.6.8. Osteoporose........................................................... 36

3.7. Associação entre os Achados Clínicos e 36

Radiográficos

3.7.1. Método de Ranawat................................................ 36

3.7.2. Método de Redlund-Johnell \& Pettersson................ 38

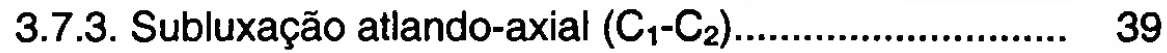

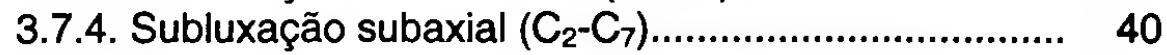

3.7.5. Erosão do processo odontóide................................ 42

3.7.6. Estreitamento discal cervical alto............................... 43

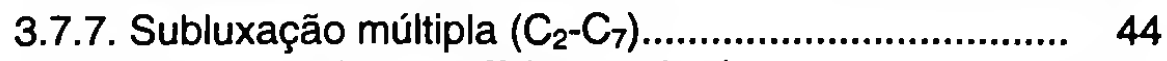

3.7.8. Esclerose da superfície vertebral............................. 45

3.7.9. Esclerose das apófises articulares........................... 46

3.7.10. Osteoporose......................................................... 47

3.7.11. Fusão óssea............................................................. 48

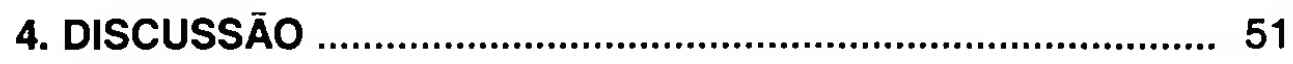

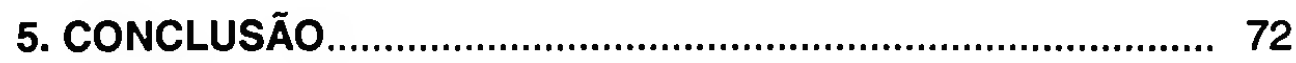

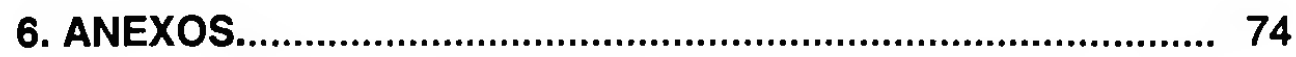

7. REFERÊNCIA BIBLIOGRÁFICA............................................. 90

SUMMARY 
RESUMO 


\section{RESUMO}

Foram estudados 81 pacientes portadores de artrite reumatóide (AR), acompanhados no Ambulatório de Imunologia do Hospital das Clínicas da Faculdade de Medicina de Ribeirão Preto da Universidade de Sào Paulo (HCFMRP - USP)

O trabalho teve como objetivo a avaliação das alterações radiográficas da coluna cervical nesses pacientes e a sua associação com sinais e sintomas clínicos, variáveis de seu quadro laboratorial e classificação em estágios segundo a American Rheumatism Association (ARA) e da capacidade funcional preconizados pelo American College of Rheumatology (ACR).

A subluxação atlanto-axial, migração superior do odontóide, a subluxação subaxial e múltipla, erosão do odontóide, estreitamento discal cervical alto, esclerose da superfície vertebral e articular, osteoporose e fusão óssea foram as variáveis radiográficos selecionados para o estudo das alterações da coluna cervical desses pacientes.

A associação entre os parâmetros foi realizada por meio do método estatístico do chi-quadrado e pelo teste exato de Fisher, foi estabelecido que a associação entre as variáveis apresentaria uma diferença significativa $(p<0,05)$.

Foi observado subluxação atlanto-axial em 10 pacientes, migração superior do odontóide em 13 pacientes, erosão do odontóide em 29 pacientes, subluxação subaxial em 5 pacientes, estreitamento discal cervical 
alto em 33 pacientes, subluxação múltipla em 4 pacientes, esclerose da superfície vertebral em 37 pacientes, esclerose das apófises articulares em 45 pacientes, osteoporose em 55 e fusão óssea em 11 pacientes.

Foram observadas associações estatisticamente significativas entre a variável do método de Ranawat com as variáveis cefaléia, sensação de crepitação, alteração dos reflexos, fraqueza muscular objetiva, classificação da capacidade funcional da AR, método de Redlund-Johnell, subluxação atlantoaxial, erosão do odontóide, esclerose da superfície vertebral, esclerose da superfície vertebral e apófise articular e fusão óssea.

As variáveis que apresentaram diferenças significativas com o método de Redlung-Johnell foram: cefaléia, alterações de reflexo, deformidade clínica nas mãos, classificação da capacidade funcional da AR, classificação em estágios da AR, subluxação atlanto-axial, erosão do odontóide e estreitamento discal cervical alto.

A variável subluxação atanto-axial apresentou associação significativa com as seguintes variáveis: perda de equilíbrio, parestesia, classificação em estágios da AR, erosão do odontóide e fusão óssea.

A variável subluxação subaxial apresentou associação significativa com os seguintes parâmetros: clonus, classificação da capacidade funcional, classificação em estágios da AR, estreitamento discal cervical alto, subluxação múltipla, esclerose da superfície vertebral, esclerose das apófises articulares e fusão óssea.

A associação da variável subluxação múltipla foi significativa com as seguintes variáveis: classificação da capacidade funcional da AR, estreitamento discal cervical alto e esclerose da superfície vertebral. 
As variáveis: erosão do odontóide, estreitamento discal cervical alto, fusão óssea, esclerose das apófises articulares e vertebral associaram-se entre si.

As alterações da artrite reumatóide estão associadas a progressão da evolução da doença. Observamos o desenvolvimento de instabilidades na coluna cervical em pacientes assintomáticos ou com mínimos achados neurológicos, indicando que a presença de sinais radiográficos de instabilidade cervical não estão necessariamente associados à presença de quadro clínico ou neurológico alterado. 
1. INTRODUÇÃO 


\section{INTRODUÇÃO}

A coluna cervical está freqüentemente acometida na artrite reumatóide (AR) como resultado da destruição das articulações, ligamentos e ossos pelo tecido sinovial patológico, que conduz à instabilidade e possível compressão dos tecidos do sistema nervoso. A prevalência de alterações na coluna cervical varia de $17 \%$ a $86 \%$ nos pacientes portadores de artrite reumatóide (SHARP et al., 1958; CONLON et al., 1966; MEIKLE \& WILKSON, 1971, SMITH et al., 1972, CABOT \& BECKER, 1978). O acometimento da coluna cervical na artrite reumatóide foi inicialmente descrito por GARROD (1890), que somente por meio de avaliação clínica detectou essas alterações em $36 \%$ de 500 pacientes portadores de artrite reumatóide estudados. A compressão medular devido à subluxação atlanto-axial foi inicialmente relatada por DAVIS \& MARKLEY (1951), e nessas últimas décadas tem havido um grande interesse no estudo deste tema, o que se comprova pelo aumento de publicações.

\subsection{Fisiopatologia}

A artrite reumatóide é uma doença inflamatória articular e de caráter sistêmico, que em ordem de prevalência acomete as articulações sinoviais das mãos e pés, e em segundo lugar, as da coluna cervical. A 
porção superior da coluna cervical apresenta considerável quantidade de tecido sinovial e por isto torna-se vulnerável às alterações anatômicas conseqüentes à destruição osteoarticular, ligamentar e sinovial, provocadas pelo pannus, que é um estado semelhante àquele visto em outras articulações (EULDERINK \& MEIJERS, 1976; CROCKARD, 1995).

Histologicamente, a AR é caracterizada por um processo inflamatório hipervascular da membrana sinovial, permeada por um infiltrado de células gigantes e outras células inflamatórias. A fibrina está presente na forma de grânulos ou disposta em camadas na cavidade e superfície articular, com a formação de folículos e infiltração linfocitária, o que é mais comumente visto na fase aguda da doença (EULDERINK \& MEIJERS, 1976; CROCKARD, 1995).

A proliferação do tecido sinovial inflamatório na coluna cervical ocorre como nas outras articulações comprometidas pela doença e com a formação de um pannus de tecido granulomatoso, havendo invasão e destruição da cartilagem articular, do osso subcondral e dos tecidos cápsulo-ligamentares (EULDERINK \& MEIJERS, 1976; ALBERT, 1995). A cartilagem hialina destas articulações sofre uma perda de substância com redução de sua altura, e o tecido de granulação formado invade a articulação, que passa por uma série de transformações patológicas intermediárias, como a fibrose, que culmina com anquilose. Nas fases finais do processo patológico pode ocorrer anquilose total ou parcial da articulação com a presença de cartilagem articular entremeada na fusão óssea (ALBERT, 1995). 
A subluxação atlanto-axial em pacientes portadores de AR deve-se à formação de um pannus que circunda o processo odontóide, que afrouxa e destrói o ligamento transverso, sendo essa a estrutura mais importante na estabilização dessa articulação (DVORAK et al.,1989; KRAMER et al., 1991; ZEIDMAN \& DUCKER, 1994).

As erosões da face posterior do processo odontóide podem contribuir nas instabilidades entre $C_{1}$ e $C_{2}$, e mais raramente nas fraturas localizadas ao nível da base do processo odontóide (EULDERINK \& MEIJERS, 1976). A subluxação atlanto-axial é passível de redução em extensão e a presença do pannus pode impedir a sua redução (CABOT \& BECKER, 1978; WEISSMAN et al.,1982; ODA et al., 1995).

A subluxação posterior de $C_{1}-C_{2}$ é rara, e quando existe está associada à lise do processo odontóide ou à destruição do arco de $\mathrm{C}_{1}$ (EULDERINK \& MEIJERS, 1976; WEISSMAN et al.,1982; KRAMER et al., 1991; GROB, 1993).

A migração superior do odontóide, também denominada de subluxação vertical ou invaginação cervical, é decorrente da destruição ósteo-cartilaginosa bilateral das facetas articulares entre o occipital, $C_{1}$ e $C_{2}$, com predominância nas massas laterais de $C_{1}$, permitindo desse modo a descida do conjunto crânio-atlantodiano, o que ocasiona penetraçāo do processo odontóide através do forâmen magno. Desse modo ocorre uma migração do crânio sobre o atlas e do atlas sobre o axis (EULDERINK \& MEIJERS, 1976). Esse deslocamento pode ser influenciado pelo uso de corticosteróides utilizados no tratamento da doença, e pela osteoporose 
decorrente da artrite reumatóide, resultante da inatividade e do processo inflamatório (EULDERINK \& MEIJERS, 1976; LIPSON, 1984; 1989). Essa migração superior do odontóide é geralmente associada a uma subluxação atlanto-axial e pode mesmo por ela ser precedida (WEISSMAN et al., 1982).

CROCKARD (1995) relatou algumas variáveis que podem influenciar na intensidade da migração do processo odontóide: extensão da erosão da massa lateral, erosão assimétrica ou simétrica, extensão da área de erosão, alterações ao redor do processo odontóide e fratura do processo odontóide. A seguir, a região subaxial é também acometida nas suas facetas articulares, ligamentos interespinhosos e discos intervertebrais (LIPSON, 1983, 1989). BALL \& SHARP (1971) demostraram que a subluxação subaxial é conseqüência da destruição do disco intervertebral, que é causada por sinovite das articulações, acompanhada de erosão do disco adjacente e do tecido ósseo. Entretanto, MARTEL (1977) mencionou que estas alterações na região subaxial seriam secundárias à artrite reumatóide e à frouxidão ligamentar, as quais conduziriam a um trauma distal crônico com alterações destrutivas.

Histologicamente ocorre a formação de osteófitos, colapso ósseo, anquilose e desenvolvimento de cifose da coluna cervical. Nas fases mais avançadas da artrite reumatóide, desenvolve-se progressivamente a inversão da lordose cervical, com redução da altura dos corpos vertebrais $\theta$ conseqüente encurtamento do pescoço, acompanhado de aumento 
acentuado da cifose cérvico-torácica, aproximando a mandíbula do manúbrio, o que dificulta a abertura da boca (CROCKARD, 1995).

A frouxidão dos ligamentos na articulação atlanto-axial, predomina nas fases iniciais da doença e quando associada à rigidez da coluna cervical sub-axial, decorrente da anquilose pós-inflamatória, é considerada fator predisponente para o desenvolvimento de subluxação na coluna cervical superior e com formação de maior quantidade de tecido inflamatório (CROCKARD, 1995)(Figura 1). O efeito proliferativo do tecido de granulação que causa compressão das estruturas neurais é agravado pelo trauma mecânico repetitivo (CROCKARD, 1995; GROB et al., 1997).

ALBERT (1995) descreveu a existência de um círculo vicioso que contribuiria para a progressão das lesões: o pannus destruiria as estruturas de estabilização da coluna e com o aumento da mobilidade, associada a essa instabilidade, ocorreria expansão do processo inflamatório.

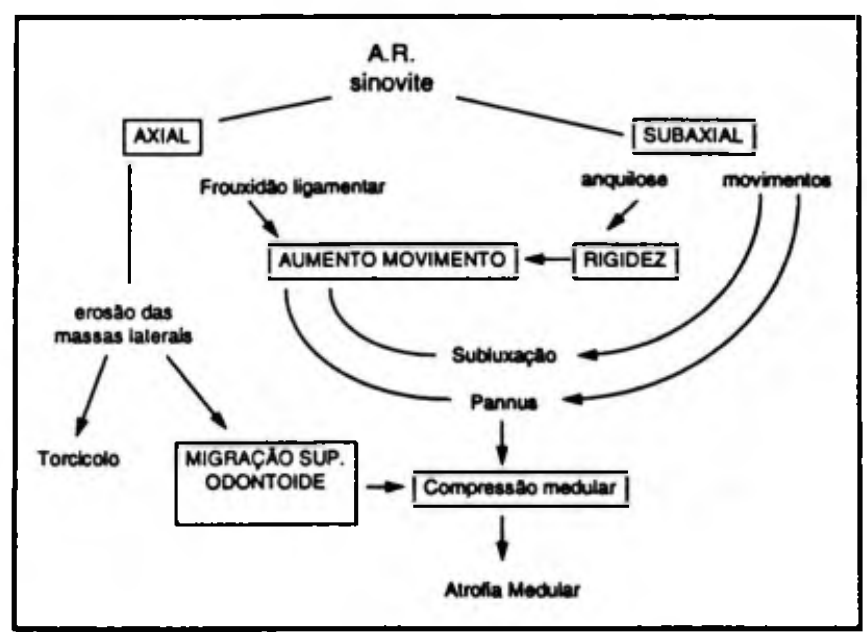

FIGURA 1- Esquema ilustrando a fisiopatologia das alteraçōes da coluna cervical na artrite reumatóide 
GROB et al. (1997) demonstraram que a formação do pannus regrediu após a estabilização cirúrgica da coluna cervical alta, sugerindo que a mobilidade desencadearia maior formação do pannus inflamatório.

A erosão do processo odontóide pode ser descrita radiograficamente como um borramento ao redor de seu contorno ósseo; afilamento apical e diminuição de sua altura verificada nas fases mais tardias da doença. Freqüentemente é observado erosão na superfície posterior do processo odontóide devido à presença de tecido sinovial localizado anteriormente ao ligamento transverso (EULDERINK \& MEIJERS, 1976). A erosão pode também ser multifocal, acometendo o processo odontóide nas faces anterior, posterior e superior e nos casos mais acentuados a erosão pode causar a sua fratura (KRAMER et al., 1991), estando relacionada com a subluxação posterior (WEISSMAN et al., 1982; LIPSON, 1985; GROB, 1993).

CABOT \& BECKER (1978) observaram a prevalência de $43 \%$ de erosão do processo odontóide em 53 pacientes e não relacionaram isoladamente essa lesão a possíveis complicações neurológicas. Pacientes com erosão do odontóide apresentaram usualmente doença avançada com elevados valores da velocidade de hemossedimentação (VHS) e fatores reumatóides positivos. 


\subsection{Evolução clínica}

Os pacientes portadores de AR podem evoluir com ou sem queixas de dor cervical e com ou sem alterações neurológicas. A dor cervical é geralmente o sintoma mais freqüente que irradia para o occipital devido à compressão do nervo grande occiptal (FEHRING \& BROOKS, 1987), o que pode ser acompanhado de rigidez e crepitação (EULDERINK \& MEIJERS, 1976; LIPSON, 1984; 1989; MENEZES et al., 1985; CROCKARD, 1995). A progressão da instabilidade pode comprimir a medula espinhal gradualmente, e apresentar dor irradiada para o membro superior, hiperreflexia e graus variáveis de perda sensitiva e déficit motor nas extremidades.

A artéria vertebral possui trajeto tortuoso natural no nível $C_{1}$ e a presença de subluxação $C_{1}-C_{2}$ pode acentuar a sua angulação, com risco de obstrução arterial durante os movimentos da coluna cervical, o que clinicamente pode ser expressada pelos sintomas de vertigem, tonturas e sensação de perda de equilíbrio (LIPSON, 1984; 1989; ALBERT, 1995).

Sintomas subjetivos como dormência, parestesias e sensação de fraqueza nas extremidades podem também estar presentes (BODEN et al., 1994).

Dificuldade para deglutir $\theta$ distúrbios de fonação são mais raramente observados, assim como a incontinência urinária, inicialmente relatada como retenção urinária (EULDERINK \& MEIJERS, 1976). Os 
pacientes, ao exame físico, apresentam relativa dificuldade na avaliação do déficit neurológico agudo (KAWAIDA et al., 1989b; DELAMARTER \& BOHLMAN, 1994); a presença de sinais de fraqueza, atrofia muscular e lesões articulares periféricas secundárias à doença reumatóide crônica podem ocultar uma possível incapacidade grave, decorrente de um comprometimento neurológico (LIPSON, 1984; 1989; BODEN, 1994; BODEN et al., 1993).

ALBERT (1995) recomendou o uso do potencial evocado dinâmico na avaliação das anormalidades neurológicas, naqueles pacientes cujas análises clínica e radiológica seriam insuficientes para o diagnóstico de um possível comprometimento neurológico, a fim de conseguir registros que não poderiam ser obtidos durante o repouso.

\subsection{Objetivo do trabalho}

Em nosso meio observamos uma carência de estudos que abordem as alterações da coluna cervical em pacientes portadores de artrite reumatóide, fato esse que nos deu uma grande motivação para a realização desta pesquisa, cujo principal objetivo foi avaliar e quantificar a real prevalência dos diferentes tipos de alterações da coluna cervical (migração superior do odontóide, subluxação atlanto-axial, subluxação subaxial, erosão do odontóide, subluxação múltipla, estreitamento discal cervical alto, esclerose superficial vertebral e articular, osteoporose e fusão óssea) em 
pacientes portadores de artrite reumatóide, que estavam rotineiramente acompanhados no Ambulatório de Imunologia do Hospital das Clínicas da Faculdade de Medicina de Ribeirão Preto da Universidade de São Paulo (HCFMRP-USP).

O estudo teve também como objetivo a averiguação da possível associação dessas alterações radiográficas da coluna cervical com os sinais e sintomas clínicos da doença, variáveis do seu quadro laboratorial, a classificação em estágios da artrite reumatóide, segundo a American Rheumatism Association (ARA) classificação da capacidade funcional da artrite reumatóide segundo 0 American College of Rheumatology (ACR) e outras variáveis relacionadas à doença. 


\section{CASUÍSTICA E MÉTODO}

\subsection{CASUÍSTICA}

Foram estudados 81 pacientes portadores de artrite reumatóide, pertencentes ao Ambulatório de Imunologia do HCFMRP-USP, sendo $25(31 \%)$ do sexo masculino e $56(69 \%)$ do feminino, com idades que variaram de 25 a 77 anos (média $53 \pm 13$ anos), no período de fevereiro de 1994 a julho de 1996.

\subsubsection{Critérios de inclusão}

A escolha dos pacientes foi realizada de modo aleatório, com inclusão dos pacientes que apresentavam diagnóstico confirmado de artrite reumatóide, segundo critérios do ACR e encontravam-se em tratamento e seguimento no Ambulatório de Imunologia do HCFMRP-USP.

\subsubsection{Critérios de exclusão}

Nove pacientes abandonaram o estudo e foram excluídos da casuística devido à falta de exames laboratoriais e radiográficos. 
O exame laboratorial nefelometria foi excluído do estudo dado à inconstância da presença de reagentes necessários a sua realização.

\subsection{MÉTODO}

\subsubsection{Métodos de avaliação}

\subsubsection{Avaliação clínica}

Foi elaborado um protocolo (Anexo A) que abrangia os principais sinais e sintomas clínicos relacionados à artrite reumatóide e que foram avaliados com a finalidade de associá-los às variáveis radiográficas estudadas.

$\mathrm{Na}$ avaliação clínica foram considerados o sexo, o início dos sintomas, a dor cervical, vertigem, tontura, cefaléia, distúrbios visuais, rigidez cervical, dor occipital, espasmo muscular, fraqueza muscular, incontinência urinária, adormecimento, perda do equilíbrio e sensação de crepitação. Sinais relacionados ao quadro neurológico, como parestesia, reflexos, sinal de Babinsky, clonus, espasticidade, fraqueza muscular 
objetiva, manifestação da artrite periférica e alterações clínicas das mãos também foram estudados na avaliação.

\subsubsection{Critério diagnóstico de artrite reumatóide}

Todos os pacientes avaliados em nosso estudo foram incluídos por meio do Critério de Diagnóstico de Artrite Reumatóide estabelecido pelo American College Rheumatology (ACR), critérios revisados de ARNETT et al. (1988).

1. rigidez matinal com duração de pelo menos 1 hora

2. artrite observada pelo médico em 3 ou mais articulações, das 14 seguintes áreas: interfalangianas proximais, metacarpofalangianas, punhos, cotovelos, joelhos, tornozelos e metarsofalangianas. Considera-se o lado direito ou esquerdo como áreas independentes.

3. artrite observada pelo médico em pelo menos 1 das articulações das mãos, ou seja, punhos, metacarpofalangianas e interfalangianas proximais.

4. artrite simétrica acometimento simultâneo da mesma articulação em ambos os lados do corpo. O acometimento das metacarpofalangianas, interfalangianas proximais $\theta$ metarsofalangianas é aceitável em absoluta simetria, por um período mínimo de 6 semanas.

5. nódulos subcutâneos sobre proeminências ósseas, superfícies extensoras ou justaarticulares observados pelo médico.

6. presença de títulos anormais de fator reumatóide, pelo menos em $5 \%$ dos controles normais.

7. alterações radiográficas características da artrite reumatóide, incluindo osteoporose periarticular $\theta$ as erosões líticas. 
O diagnóstico de artrite reumatóide é considerado quando existe pelo menos 4 desses 7 critérios. Os critérios de 1 a 4 devem estar presentes por um período mínimo de 6 semanas.

\subsubsection{Classificação da capacidade funcional de} artrite reumatóide

Após o exame clínico os pacientes foram classificados em diferentes graus, de acordo com a ACR, critérios revisados de HOCHBERG et al. (1992).

Classe I- completa habilidade para realizar todas as atividades de vida diária sem dificuldade (vocacional e não vocacional).

Classe II - adequada para atividades de cuidados próprios e atividades vocacionais, mas limitado a atividades não vocacionais.

Classe III - limitada - somente para atividades de cuidados próprios, mas limitado a atividades vocacionais e não vocacionais.

Classe IV - incapacidade total ou grave - limitado para realizar cuidados próprios, vocacionais e não vocacionais.

Vocacional (trabalho, escola e serviços domésticos)

Não vocacional (recreação e lazer) 


\subsubsection{4- Classificação em estágios da artrite reumatóide segundo a American Rheumatism Association} (ARA)

Todos os pacientes foram submetidos a exames radiográficos e as possiveis lesões destrutivas das articulações das mãos e dos punhos foram avaliadas e associadas ao exame físico do paciente, com a finalidade de incluí-los nos estágios estabelecidos pela ARA (STEINBROKER et al., 1949).

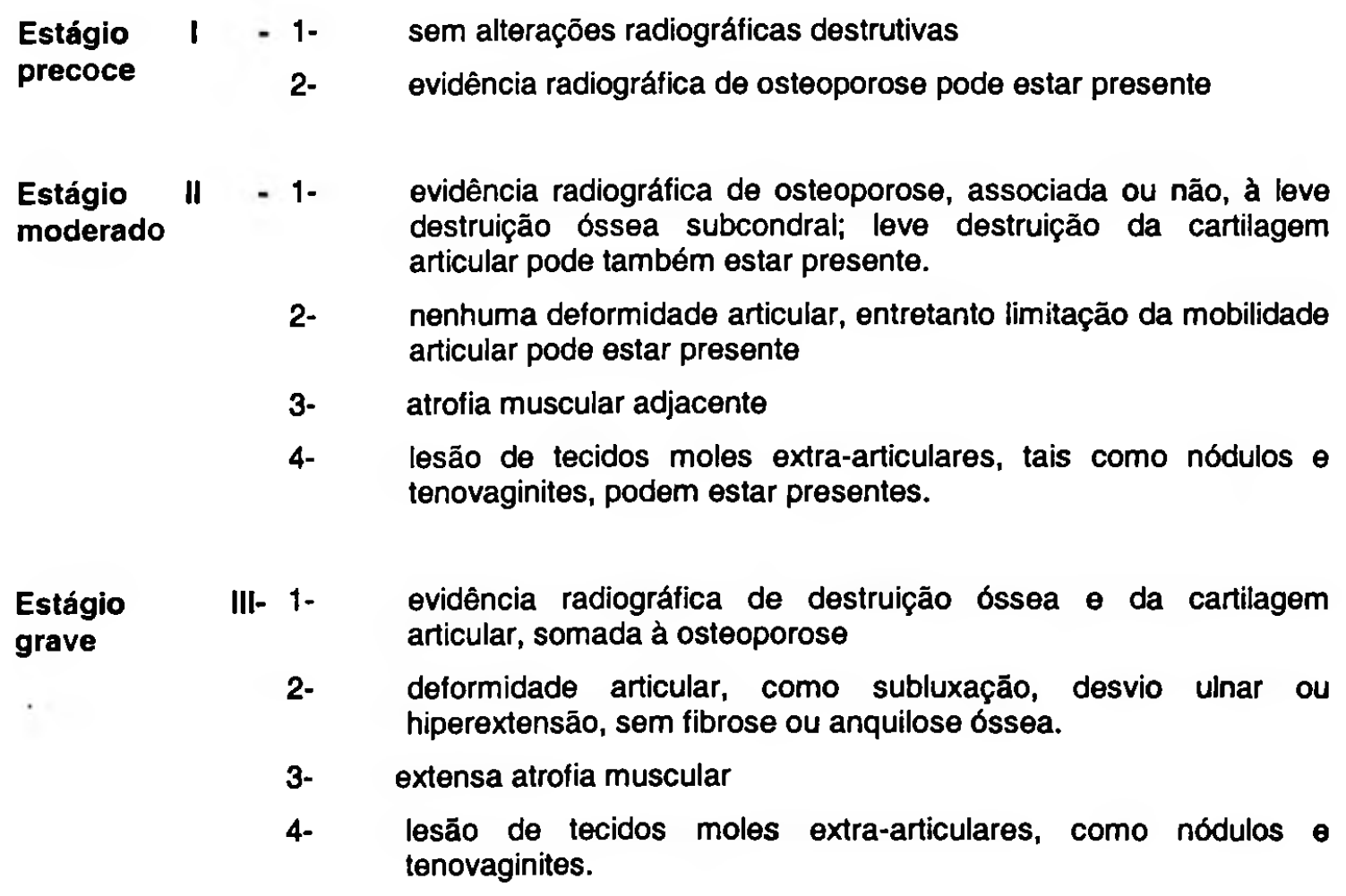

Estáglo IV- 1- fibrose ou anquilose óssea

terminal

2- critérios do estágio III 


\subsubsection{Avaliação laboratorial}

Foram realizados os seguintes exames laboratoriais: látex, Waaler-Rose, velocidade de hemossedimentação (VHS), proteína C reativa e mucoproteína, com a finalidade de associá-los às variáveis estudadas na coluna cervical.

\subsubsection{Avaliação radiográfica}

Todos os pacientes foram submetidos à avaliação radiográfica da coluna cervical e das mãos. As radiografias da coluna cervical foram realizadas nas posições: ântero-posterior (AP), perfil neutro, perfil em flexão máxima e perfil em extensão máxima, enquanto que as radiografias das mãos foram realizadas nas posições em AP e oblíquas.

Para a realização das radiografias da coluna cervical a ampola do aparelho de raio-x foi mantida a uma distância de $1,5 \mathrm{~m}$ do chassi, com o feixe de raios direcionados em C2.

Os exames radiográficos das mãos foram utilizados para o estadiamento da doença segundo a classificação em estágios da artrite reumatóide (AR), segundo a ARA.

Os exames radiográficos da coluna cervical foram utilizados para a avaliação da instabilidade dos diferentes segmentos da coluna cervical e também verificação das outras possíveis alterações ocasionadas pela doença, utilizou-se a mensuração pelo método de Ranawat, 
Redlund-Johnell \& Peterson, McGregor, White \& Panjab e medida da instabilidade $\mathrm{C}_{1}-\mathrm{C}_{2}$.

\subsection{Método de Ranawat}

A mensuração da migração superior do odontóide pelo método de RANAWAT (1979) foi realizada pela medida da distância de uma linha perpendicular, partindo do centro do pedículo do axis à outra linha que conectava o arco anterior ao posterior do atlas (Figura 2). A migração superior do odontóide foi diagnosticada quando a distância apresentada era menor que $13 \mathrm{~mm}$ no sexo feminino e $15 \mathrm{~mm}$ no sexo masculino.

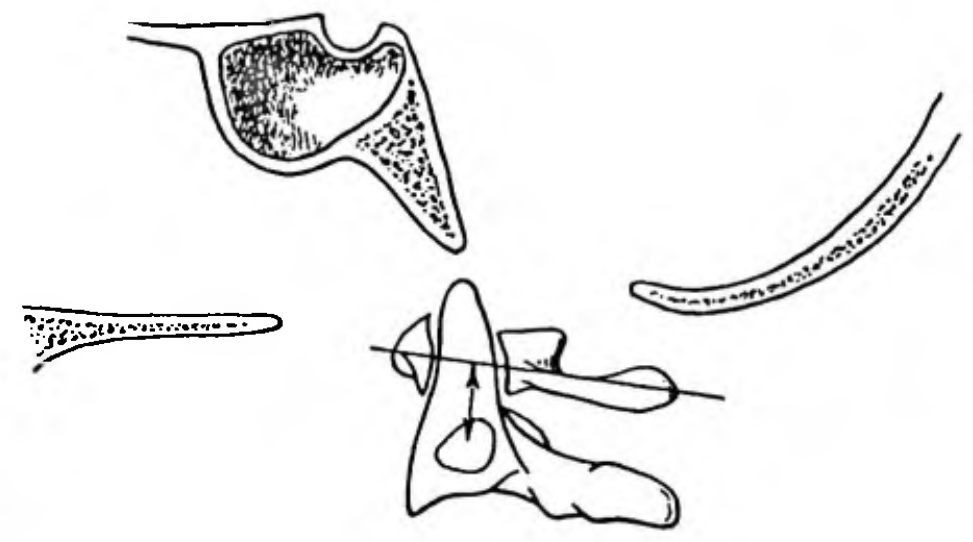

FIGURA 2 - Desenho ilustrando a medida pelo método de Ranawat

\subsection{Método de Redlund-Johnell \& Pettersson}

Os valores do método de REDLUD-JOHNELL \& PETERSSON (1984) foram determinados por meio da distância perpendicular entre a linha de McGregor na porção superior $\theta$ inferiormente 
pelo ponto médio da margem inferior do corpo do axis, sendo essas linhas traçadas nas radiografias em perfil na posição neutra (Figura 3). A migração superior do odontóide foi considerada quando a distância era menor que $29 \mathrm{~mm}$ no sexo feminino e $34 \mathrm{~mm}$ no sexo masculino.

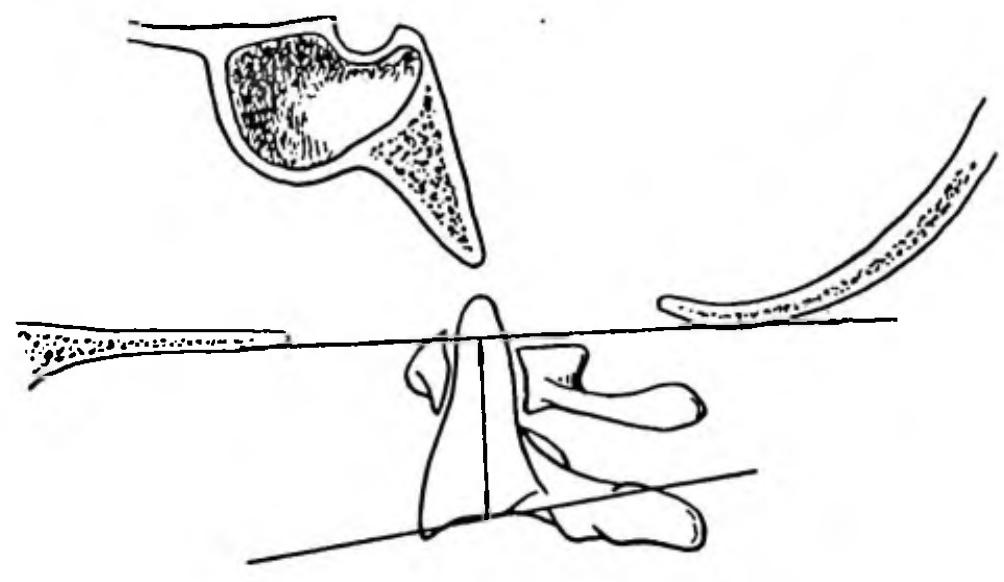

FIGURA 3 - Desenho ilustrando a medida pelo método de Redlund-Johnell

\subsection{Método de McGregor}

O método descrito por McGREGOR (1948) foi utilizado para a determinação da linha que passava pela base do osso occipital ao pálato duro nas radiografias em perfil.

\subsection{Subluxação atlanto-axial $\left(C_{1}-C_{2}\right)$}

A subluxação atlanto-axial foi avaliada por meio de radiografias obtidas em perfil, na posição neutra, flexão máxima e extensão máxima, considerou-se a presença de subluxação quando a distância entre a margem anterior do processo odontóide e o bordo posterior 
do arco do atlas era maior que $3 \mathrm{~mm}$ (Figura 4). Consideramos o diagnóstico de subluxação atlanto-axial nas radiografias da coluna cervical em perfil neutro e/ou em flexão. A posição de extensão máxima foi utilizada para avaliar se a lesão era redutível ou irredutível pela normalização da distância entre o arco de $\mathrm{C}_{1}$ e o processo odontóide.

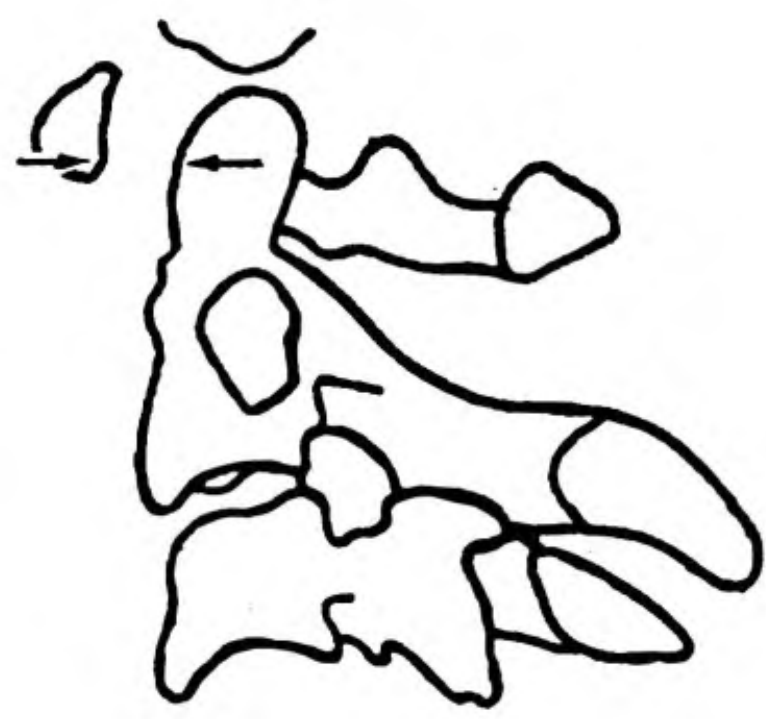

FIGURA 4 - Desenho ilustrando a medida da instabilidade $C_{1}-C_{2}$

\subsubsection{5.- Subluxação subaxial e múltipla $\left(C_{2}-C_{7}\right)$}

A presença de subluxação subaxial e múltipla foi avaliada pelo método de WHITE-PANJABI (1987), obtido por meio da mensuração em radiografias da coluna cervical em perfil dinâmico. $A$ translação vertebral foi determinada por meio da mensuração da distância entre uma linha que passava pelo bordo posterior do corpo vertebral adjacente $\theta$ outra que passava pelo bordo posterior do corpo vertebral subjacente; a diferença 
entre essas linhas indicava instabilidade quando seu valor era superior a 3,5 $\mathrm{mm}$ (Figura 5). A angulação vertebral era medida por meio de um ângulo formado pelas linhas que passavam pelo bordo posterior dos corpos vertebrais adjacente e subjacente. A formação de um ângulo entre estas duas linhas, quando maior que 11 graus indicava instabilidade vertebral (Figura 6). A instabilidade angular e/ou a translação vertebral foram consideradas como sendo subluxação subaxial.

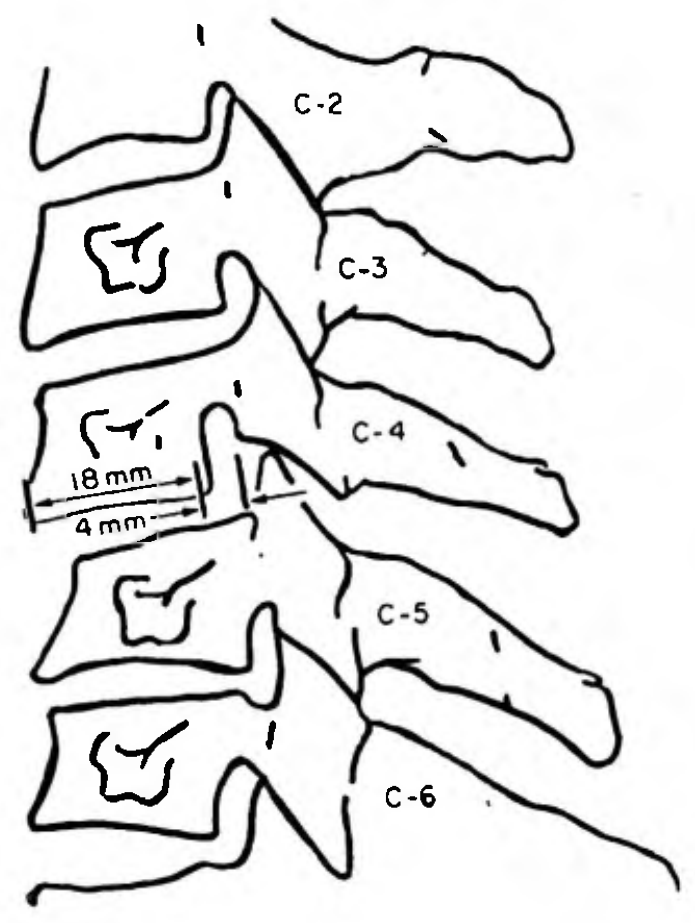

FIGURA 5 - Desenho ilustrando a translação vertebral 


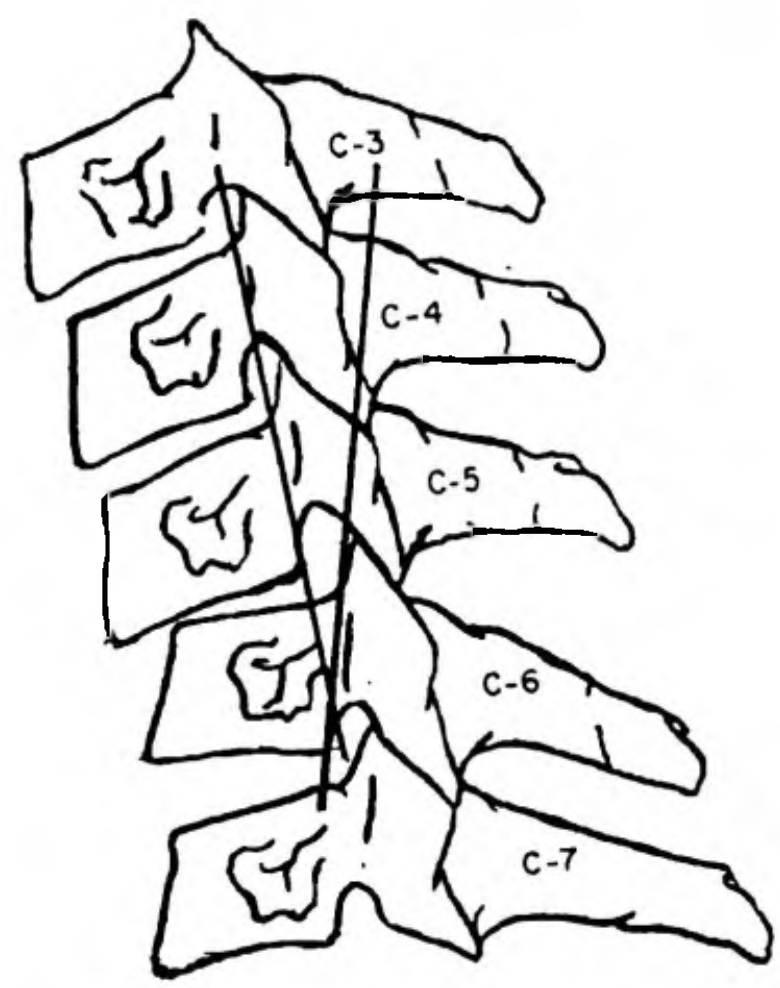

FIGURA 6 - Desenho ilustrando a angulação vertebral

\subsubsection{Alteraçōes degenerativas}

As lesões como erosão do processo odontóide, pinçamento do disco intervertebral, erosão e esclerose vertebral, fusão óssea ou ainda a presença de osteoporose foram consideradas como alterações degenerativas decorrentes da artrite reumatóide, e sua correlação com os sintomas clínicos também foi analisada no estudo. 


\subsubsection{Estudo das associaçōes entre as}

\section{variáveis estudadas}

Os dados clínicos e laboratoriais, obtidos por meio da avaliação dos pacientes, foram individualmente associados às variáveis utilizadas na avaliação radiográfica, que foi realizada pelo método estatístico do chi-quadrado $\left(x^{2}\right)$. O teste exato de Fisher (bi-caudal) foi utilizado quando a prevalência de alguma variável foi insuficiente para realização do método do chi-quadrado $\left(x^{2}\right)$. Foi estabelecido um valor $(p<0,05)$ para a determinação da significância estatística. A coleta dos dados clínicos, radiológicos e laboratoriais, obtida por meio do protocolo utilizado, forneceu 55 variáveis que foram associadas às alterações radiográficas utilizadas para a avaliação da instabilidade cervical.

$\mathrm{Na}$ análise estatística utilizou-se os seguintes programas :

- GraphPad InStat tm (1990 - 1994) - V2.0a

- Epilnfo 6 (1994) - V6.04b 


\section{RESULTADOS}




\section{RESULTADOS}

\subsection{Avaliação clínica}

A avaliação clínica dos pacientes, segundo as variáveis que foram selecionadas (dor cervical, vertigem, tontura, cefaléia, distúrbios visuais, rigidez cervical, dor occipital, espasmo muscular, fraqueza muscular subjetiva, incontinência urinária, adormecimento, perda de equilíbrio e sensação de crepitação) está representada na tabela 1. Dos 81 pacientes avaliados, somente $4(5 \%)$ não apresentaram dor ou nenhum sintoma no momento da avaliação, enquanto que 77 (95\%) apresentaram, pelo menos, um dos sintomas selecionados para o estudo, apesar de ser observado grande variação nas suas prevalências.

A dor cervical esteve presente em 44 pacientes $(55 \%)$, sendo de intensidade leve em $22(26 \%)$, moderada em $14(17 \%)$ e grave em $8(10 \%)$ pacientes. Quarenta e cinco $(55,5 \%)$ referiam fraqueza muscular subjetiva, 37 (45\%) referiam tonturas, 36 (44\%) distúrbios visuais, 34 (41,9\%) adormecimento dos membros , 33 (40\%) dor occipital, 31 (38\%) cefaléia, 30 (37\%) perda do equilíbrio, 26 (32\%) sensação de crepitação cervical, 22 (27\%) rigidez cervical, $9(11 \%)$ espasmo muscular $\ominus 1(1,2 \%)$ incontinência urinária.

Quanto à incidência de migração superior do odontóide, os resultados foram reunidos em 3 grupos, de acordo com o tempo do início da 
doença: grupo I (0 - 5 anos) apresentou 2 casos, grupo II (> 5 - 10 anos) apresentou 3 casos, grupo III (> 10 anos) apresentou 8 casos, todos mensurados tanto pelo método de Ranawat como de Redlund-Johnell.

Tabela 1 - Prevalência dos sintomas clínicos obtidos na avaliação clínica

\begin{tabular}{lcl}
\hline Sintomas & $\mathbf{n}^{\mathbf{9}}$ Pacientes & $\%$ \\
\hline Fraqueza muscular subjetiva & 45 & 55,5 \\
Dor cervical & 44 & 55 \\
Tontura & 37 & 45 \\
Distúrbios visuais & 36 & 44 \\
Dormência nos membros & 34 & 42 \\
Dor occipital & 33 & 40 \\
Cefaléia & 31 & 38 \\
Perda de equilíbrio & 30 & 37 \\
Crepitação cervical & 26 & 32 \\
Rigidez cervical & 22 & 27 \\
Espasmo muscular & 9 & 11 \\
Incontinência urinária & 1 & 1,2 \\
\hline
\end{tabular}

A avaliação neurológica dos pacientes está representada na tabela 2 e foram observados os seguintes sintomas: fraqueza muscular objetiva em $19(23,4 \%)$, parestesia em 18 (22,2\%), hiperreflexia em 13 (16\%), diminuição dos reflexos em 15 (18,5\%), clonus em 5 (6,2\%), paresia em $2(2,5 \%)$ e espasticidade em $1(1,2 \%)$ paciente; em nenhum dos pacientes foi observado sinal de Babinsky. 
Tabela 2 - Resultados da avaliação neurológica

\begin{tabular}{lcc}
\hline Avaliação neurológica & $\mathbf{n}^{\mathbf{2}}$ Pacientes & $\%$ \\
\hline Fraqueza muscular objetiva & 19 & 23,4 \\
Parestesia & 18 & 22,2 \\
Reflexos diminuidos & 15 & 18,5 \\
Reflexos aumentados & 13 & 16,0 \\
Clonus & 5 & 6,2 \\
Paresia & 2 & 2,5 \\
Espasticidade & 1 & 1,2 \\
Babinsky & 0 & 0 \\
\hline
\end{tabular}

Manifestação de artrite periférica foi observada em todos os pacientes, enquanto que a deformidade clínica da mão foi observada em 59 $(72,8 \%)$ pacientes.

\subsection{Avaliação laboratorial}

Os resultados das variáveis laboratoriais estudados estão representadas na tabela 3 , e foi observado que $75(92,6 \%)$ pacientes eram fator reumatóide positivos, $73(90,1 \%)$ apresentavam teste do latex positivo, $66(81,5 \%)$ teste de Waaler-Rose positivo, 79 (97,5\%) velocidade de hemossedimentação (VHS) aumentada, 75 (92,6\%) apresentavam proteína C reativa e $74(91,3 \%)$ reação positiva de mucoproteínas. 
Tabela 3 - Prevalência dos resultados positivos dos parâmetros utilizados na avaliação laboratorial

\begin{tabular}{lcc}
\hline Teste laboratorial & $\mathrm{n}^{2}$ Pacientes & $\%$ \\
\hline Fator reumatóide positivo & 75 & 92,6 \\
Latex & 73 & 90,1 \\
Waaler-rose & 66 & 81,5 \\
VHS & 79 & 97,5 \\
PCR & 75 & 92,6 \\
Mucoproteínas & 74 & 91,3 \\
\hline
\end{tabular}

\subsection{Avaliação clínica segundo os critérios do American College of Rheumatology (ACR)}

A tabela 4 ilustra os dados obtidos segundo a avaliação clínica, utilizando-se os critérios preconizados pela ACR. Foi observado rigidez matinal nas mãos em $79(97,5 \%)$ pacientes, artrite em 3 ou mais articulações em 81 (100\%) pacientes, artrite simétrica em 81 (100\%), nódulos subcutâneos em $8(9,9 \%)$, títulos anormais de fator reumatóide em $73(90,1 \%)$ e alterações radiográficas características da artrite reumatóide em $60(74,1 \%)$. 
Tabela 4 - Prevalência das variáveis utilizadas na avaliação clínica segundo critérios do ACR

\begin{tabular}{lcc}
\hline Critérios da ACR & n Pacientes & $\%$ \\
\hline Rigidez matinal das mãos & 79 & 97,5 \\
Artrite em 3 ou mais articulações & 81 & 100 \\
Artrite simétrica & 81 & 100 \\
Nódulos subcutâneos & 8 & 9,9 \\
Títulos anormais de F.R. & 73 & 90,1 \\
Alteração radiog. caract. A.R. & 60 & 74,1 \\
\hline
\end{tabular}

\subsection{Classificação em estágios da artrite reumatóide} (AR) segundo a American Rheumatism Association (ARA)

A classificação em estágios do grupo de pacientes estudados, de acordo com os critérios preconizados pela ARA está ilustrada na tabela 5. Foi observado que $17(21 \%)$ pacientes enquadravam-se no estágio I, 24 $(29,6 \%)$ no estágio II, $34(42 \%)$ no estágio III e $6(7,4 \%)$ no estágio IV.

Tabela 5 - Número e freqüência dos pacientes segundo a classificação em estágios de artrite reumatóide segundo a ARA

\begin{tabular}{ccl}
\hline Grau & $\mathbf{n}^{2}$ de pacientes & $\%$ \\
\hline I & 17 & 21,0 \\
II & 24 & 29,6 \\
III & 34 & 42,0 \\
IV & 6 & 7,4 \\
\hline Total & 81 & \\
\hline
\end{tabular}




\subsection{Classificação da capacidade funcional}

\section{de artrite reumatóide}

A classificação do grupo de pacientes estudados, obedecendo-se a classificação da capacidade funcional de AR, mostrou que $38(46,9 \%)$ pacientes enquadravam-se na classe I, 30 (37\%) na classe II, $11(13,6 \%)$ na classe III e 2 (2,5\%) na classe IV (Tabela 6).

Tabela 6 - Número e percentual dos pacientes segundo a classificação de capacidade funcional de AR (classes)

\begin{tabular}{ccc}
\hline Classe & $\mathbf{n}^{2}$ de Pacientes & $\%$ \\
\hline I & 38 & 46,9 \\
II & 30 & 37,0 \\
III & 11 & 13,6 \\
Total & 2 & 2,5 \\
\hline
\end{tabular}

\section{6- Avaliação radiográfica}

Os resultados da avaliação radiográfica estão ilustrados na tabela 7. Foi observado que dentre os 81 pacientes estudados, $65(80,2 \%)$ 
apresentavam alterações radiográficas de acordo com as diferentes variáveis utilizadas na avaliação e $22(27,2 \%)$ apresentavam algum tipo de instabilidade como: migração superior do odontóide, subluxação atlandoaxial, subluxação subaxial e subluxação múltipla.

Tabela 7 - Prevalência das alterações radiográficas da coluna cervical no grupo de pacientes estudados

\begin{tabular}{lcc}
\hline Variáveis radiográficas & $n^{2}$ Pacientes & $\%$ \\
\hline MSO* (Ranawat) $^{*}$ & 9 & 11,1 \\
MSO* (Redlund-Johnell) & 11 & 13,6 \\
Subluxação atlanto-axial $\left(\mathrm{C}_{1}-\mathrm{C}_{2}\right)$ & 10 & 12,5 \\
Subluxação subaxial $\left(\mathrm{C}_{2}\right.$ a $\left.\mathrm{C}_{7}\right)$ & 5 & 6,2 \\
Subluxação múltipla & 4 & 4,9 \\
Erosão do odontóide & 29 & 35,8 \\
Estreitamento discal cervical alto & 33 & 40,7 \\
Esclerose superfície vertebral & 37 & 45,7 \\
Esclerose apófise articular & 45 & 55,5 \\
Osteoporose & 55 & 67,9 \\
Fusão óssea & 11 & 13,6 \\
\hline
\end{tabular}




\subsubsection{MÉTODO DE RANAWAT}

A avaliação radiográfica segundo o método de Ranawat apresentou resultados positivos em 9 (11\%) pacientes, indicando migração superior do odontóide (subluxação vertical) (Figura 7).

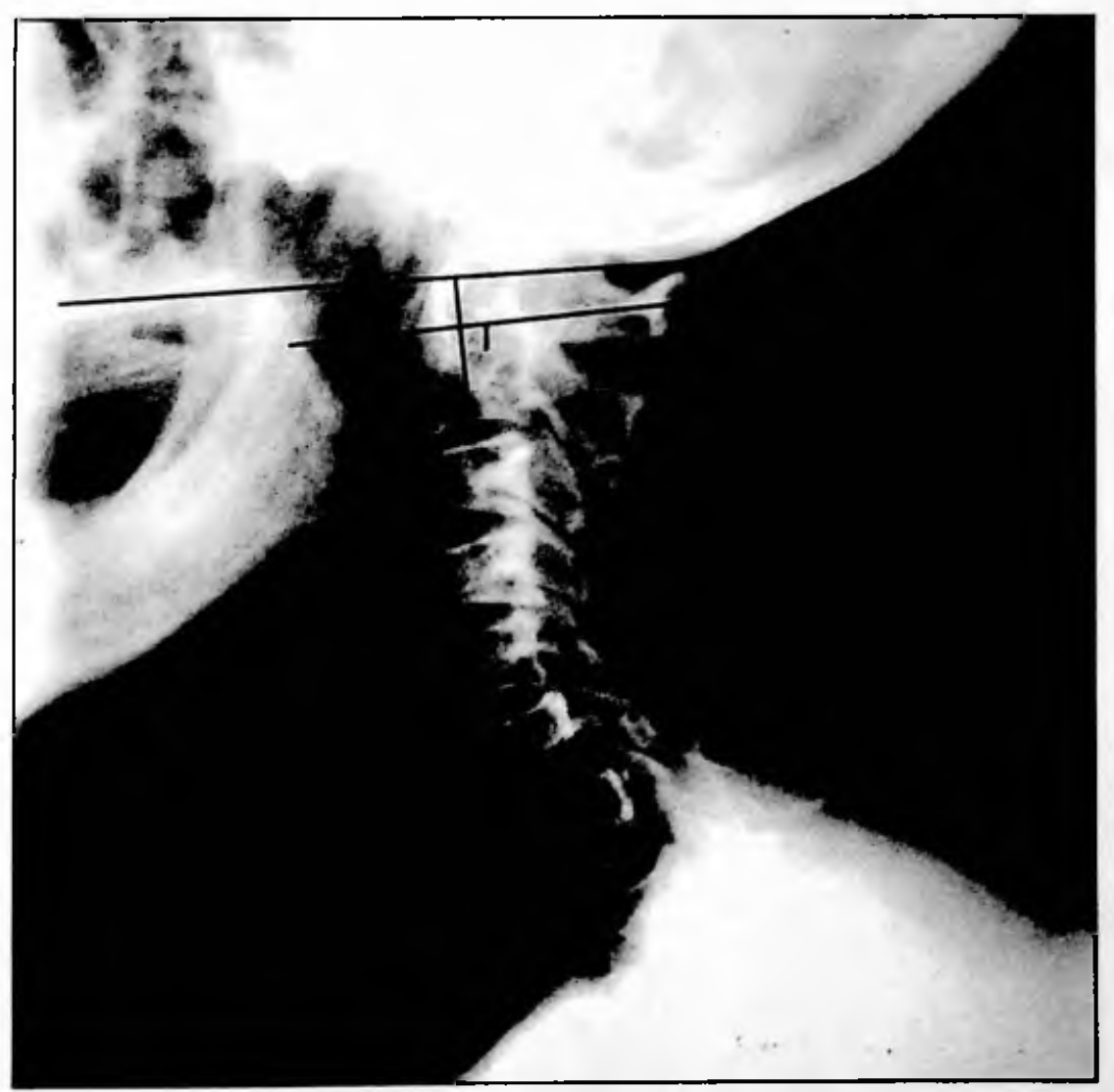

FIGURA 7 - Radiografia em perfil da coluna cervical ilustrando as alterações das medidas segundo o método de Ranawat (R.A.- $11 \mathrm{~mm}$ ) e Redlund-Johnell (R.L.- 27mm). Observar a presença de erosão do processo odontóide. 


\subsubsection{MÉTODO DE REDLUND-JOHNELL}

A avaliação radiológica segundo o método de Redlund-Johnell apresentou resultados positivos em 11 (13,5\%) pacientes (Figura 7), indicando migração superior do processo odontóide (subluxação vertical).

\subsubsection{SUBLUXAÇÃO ATLANTO-AXIAL (C1-C2)}

Foi observado instabilidade atlanto-axial em 10 (12,3\%) pacientes, determinada pela distância entre a face anterior do processo odontóide e bordo posterior do arco do atlas, obtidas nas radiografias dinâmicas em perfil (Figura 8).
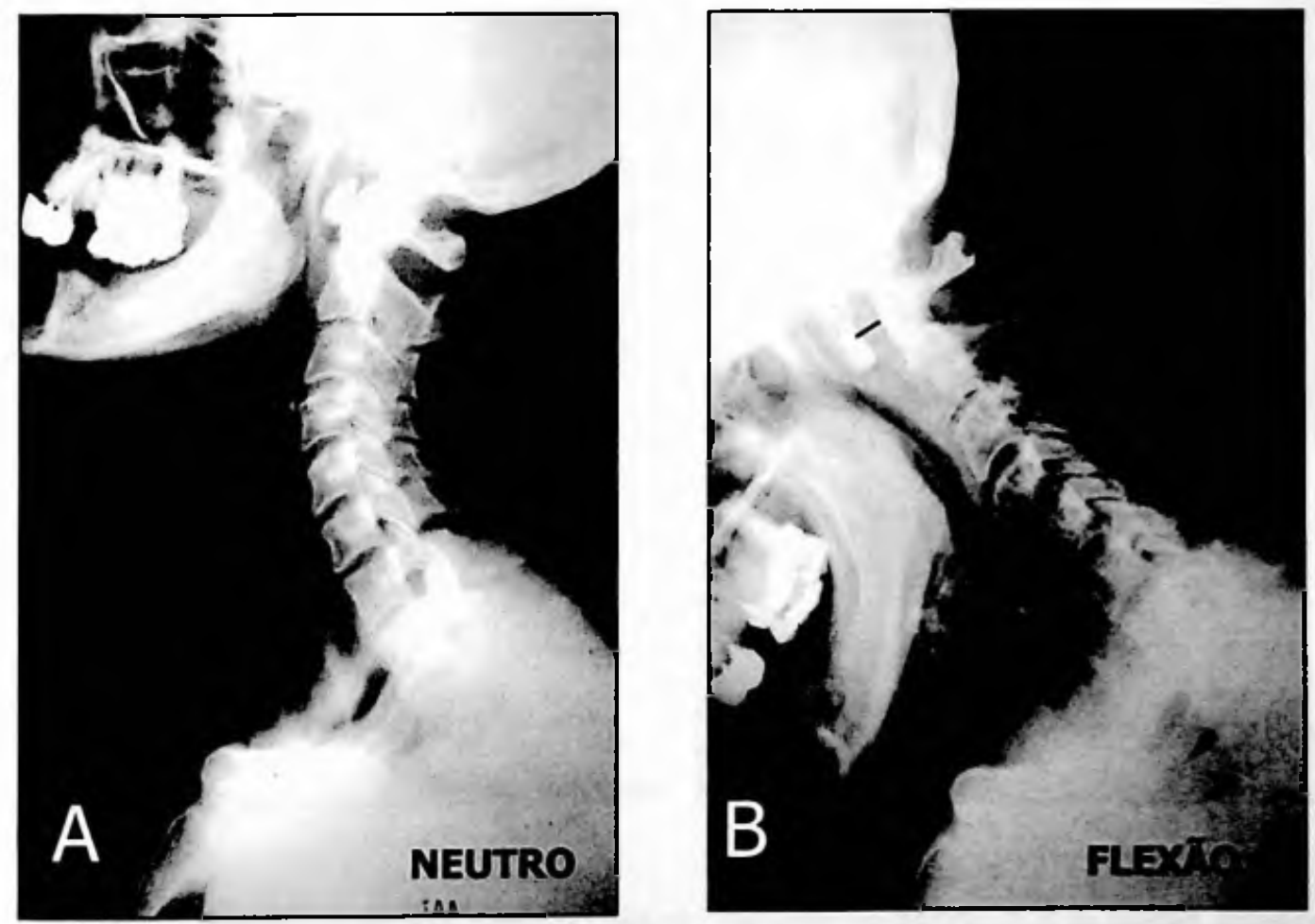

FIGURA 8 - Radiografias em perfil da coluna cervical ilustrando a subluxação atlanto-axial (C1-C2).

A- Radiografia em perfil na posição neutra.

B- Radiografia de perfil na posição de hiperflexão. Observar o aumento da distância do bordo anterior do processo odontóide ao bordo posterior do arco de C1 (7mm). 
B- Radiografia de perfil na posição de hiperflexão. Observar o aumento da distância do bordo anterior do processo odontóide ao bordo posterior do arco de $\mathrm{C} 1(7 \mathrm{~mm})$.

\subsubsection{SUBLUXAÇÃO SUBAXIAL (C2-C7)}

A instabilidade nos segmentos inferiores da coluna cervical, avaliada por meio de radiografias dinâmicas em perfil, foi observada em $5(6 \%)$ pacientes (Figura 9).
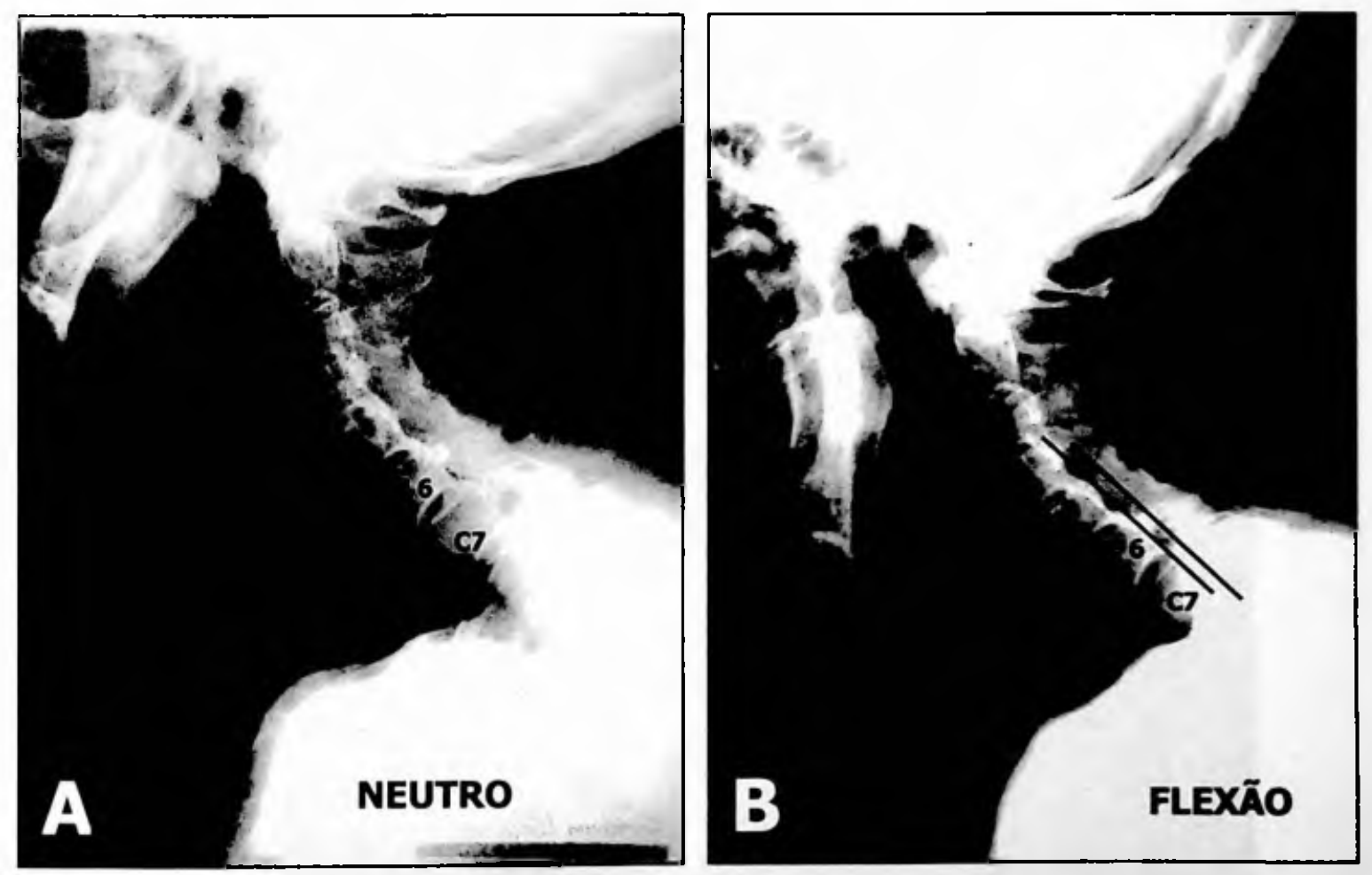

FIGURA 9 - Radiografias em perfil do coluna cervical ilustrando a subluxaçāo subaxial $\theta$, erosão do processo odontóide e fusão óssea de C2-C5.

A- Radiografia em perfil da coluna cervical na posição neutra, $\theta$ a presença de erosão em torno do processo odontóide.

B- Radiografia em perfil na posição de hiperflexão. Observar o deslocameto anterior de C6-C7 $(4,5 \mathrm{~mm})$

\subsubsection{EROSÃO DO PROCESSO ODONTÓIDE}


A erosão do processo odontóide foi observada em 29 (35,8\%) pacientes. Não foi possível estabelecer um padrão uniforme dessa alteração, tendo sido observado a erosão em diferentes partes do processo odontóide (apical, face anterior e face posterior) (Figura 7 e 9).

\subsubsection{FUSÃO ÓSSEA}

Foi observado fusão óssea, em um ou mais niveis, dos corpos vertebrais em $11(13,5 \%)$ pacientes (Figura 9).

\subsubsection{SUBLUXAÇÃO MÚLTIPLA}

A subluxação múltipla representa um tipo de instabilidade do segmento subaxial da coluna cervical, tendo sido observada em 4 (4,9\%) pacientes (Figura 10).

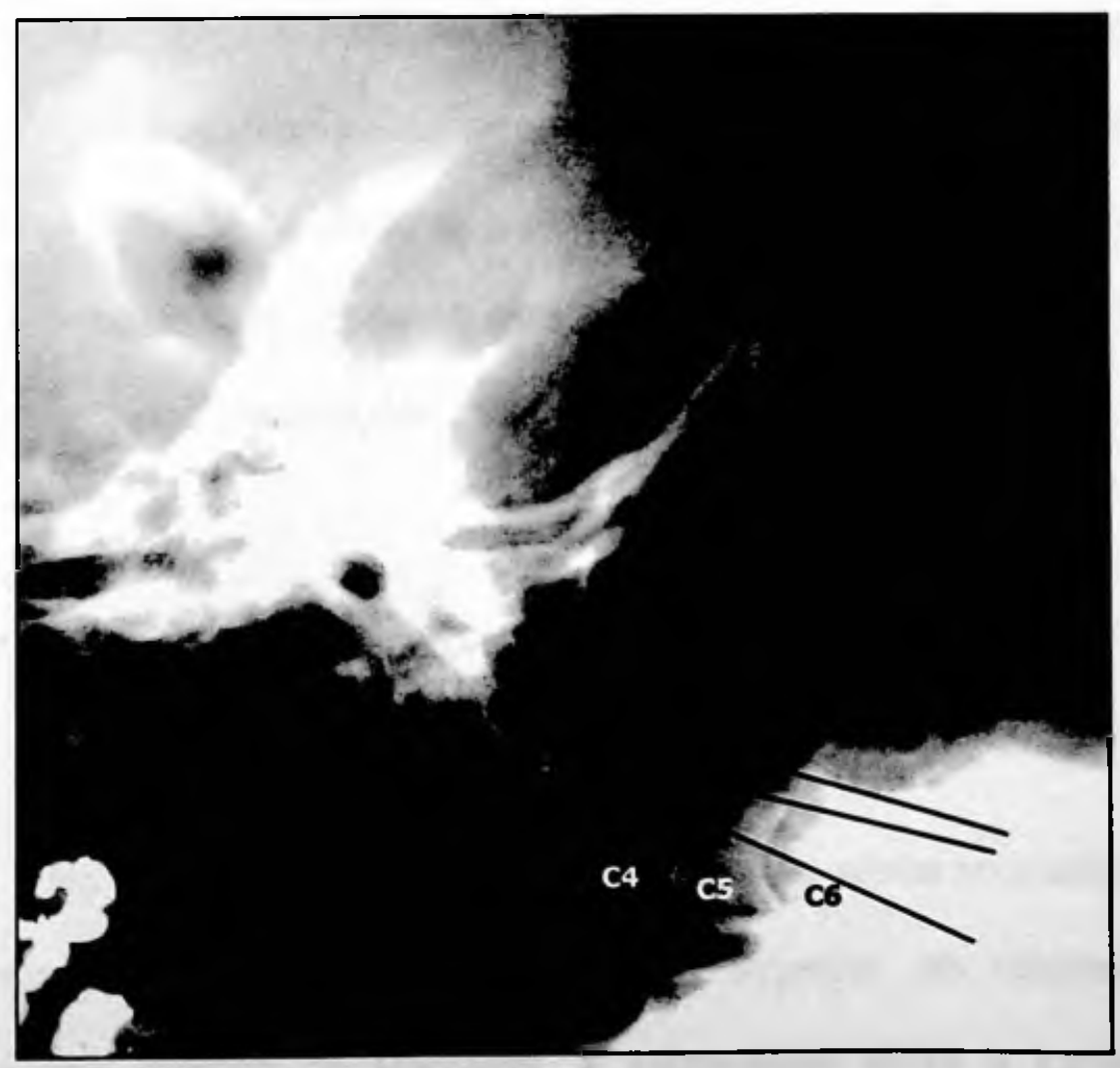




\subsubsection{Osteoporose}

A osteoporose da coluna cervical avaliada por meio de radiografias, foi observada em $55(67,9 \%)$ dos pacientes.

\subsection{Associação entre os achados clínicos e} radiográficos

A associação entre os achados clínicos e radiográficos foi verificada considerando-se cada variável radiográfica de modo isolado, que foi confrontado com as variáveis clínicas, laboratoriais e também radiográficas, utilizando-se o teste estatístico chi-quadrado $\left(x^{2}\right)$; quando a freqüência em algumas categorias de alguma variável não foi suficiente para realização do teste do chi-quadrado $\left(x^{2}\right)$, utilizou-se o teste exato de Fisher, tendo sido estabelecida uma diferença estatística significativa $(p<0,05)$. Os resultados gerais destas associações estão detalhados no ANEXO B.

\subsubsection{Método de Ranawat}

No grupo de 81 pacientes portadores de artrite reumatóide, foram encontrados 9 pacientes com migração superior do odontóide diagnosticada pelo método de Ranawat. A associação entre a variável 
Ranawat $e$ as seguintes variáveis com diferença estatística significativa $(p<0,05)$ está representada na tabela 8 .

Tabela 8 - Associação entre a avaliação radiográfica de instabilidade cervical pelo método de Ranawat e demais variáveis estudadas

\begin{tabular}{|c|c|c|c|}
\hline \multirow{2}{*}{ Variáveis } & \multirow{2}{*}{$\begin{array}{c}\text { Valor da } \\
\text { diferença } \\
\text { signiflcativa } \\
\text { (p)* }\end{array}$} & \multicolumn{2}{|c|}{ Método de Ranawat } \\
\hline & & $\begin{array}{l}\text { Valor (-) } \\
n=72\end{array}$ & $\begin{array}{c}\text { Valor }(+) \\
n=9\end{array}$ \\
\hline Cefaléia (ausência) & 0,011 & $57 \%(41 / 72)$ & $100 \%(9 / 9)$ \\
\hline Rigidez cervical & 0,056 & $24 \%(17 / 72)$ & $55 \%(5 / 9)$ \\
\hline Sensação de crepitação & 0,040 & $26 \%(19 / 72)$ & $78 \%(7 / 9)$ \\
\hline Alteração dos reflexos & 0,0006 & $28 \%(20 / 72)$ & $89 \%(8 / 9)$ \\
\hline Fraqueza muscular (objetiva) & 0,022 & $18 \%(13 / 72)$ & $55 \%(5 / 9)$ \\
\hline $\begin{array}{l}\text { Classificação capacidade } \\
\text { funcional da AR }\end{array}$ & 0,0001 & $8 \%(6 / 72)$ & $78 \%(7 / 9)$ \\
\hline Classificaçāo em estágios AR & 0,014 & $4 \%(3 / 72)$ & $89 \%(8 / 9)$ \\
\hline Redlund-Johnell & 0,0001 & $5 \%(4 / 72)$ & $78 \%(7 / 9)$ \\
\hline Subluxação atlanto-axial & 0,011 & $8 \%(6 / 72)$ & $44 \%(4 / 9)$ \\
\hline Erosão odontóide & 0,049 & $32 \%(23 / 72)$ & $66 \%(6 / 9)$ \\
\hline Esclerose superfície vertebral & 0,044 & $42 \%(30 / 72)$ & $79 \%(7 / 9)$ \\
\hline Esclerose apófises articulares & 0,038 & $44 \%(32 / 72)$ & $88 \%(8 / 9)$ \\
\hline Osteoporose & 0,051 & $64 \%(46 / 72)$ & $100 \%(9 / 9)$ \\
\hline Fusão óssea & 0,017 & $10 \%(7 / 72)$ & $44 \%(4 / 9)$ \\
\hline
\end{tabular}

- Teste exato de Fisher 


\subsubsection{Método de Redlund-Johnell \& Pettersson}

Entre os 81 pacientes portadores de artrite reumatóide, foram encontrados 11 com migração superior do odontóide que foi diagnosticada pelo método de Redlund-Johnell. Os valores da avaliação radiográfica, obtidos pelo método de Rendlund-Johnell, quando confrontados com as demais variáveis estudadas, demonstraram haver diferença significativa $(p<0,05)$ (Tabela 9$)$.

Tabela 9 - Associação entre a avaliação de instabilidade cervical pelo método de Redlund-Johnell e diferentes variáveis estudadas

\begin{tabular}{|c|c|c|c|}
\hline \multirow{2}{*}{ Variávels } & \multirow{2}{*}{$\begin{array}{c}\text { Valor da } \\
\text { diferença } \\
\text { significativa } \\
\text { (p) }\end{array}$} & \multicolumn{2}{|c|}{ Rendlund-Johnell } \\
\hline & & $\begin{array}{l}\text { Valor }(-) \\
\qquad n=70\end{array}$ & $\begin{array}{c}\text { Valor }(+) \\
n=11\end{array}$ \\
\hline Tontura (ausência) & 0,058 & $50 \%(35 / 70)$ & $82 \%(9 / 11)$ \\
\hline Cefaléia (ausência) & 0,044 & $57 \%(40 / 70)$ & $91 \%(10 / 11)$ \\
\hline Alteração reflexo & 0,041 & $30 \%(21 / 70)$ & $64 \%(7 / 11)$ \\
\hline Alterações clínicas nas mãos & 0,030 & $68 \%(48 / 70)$ & $100 \%(11 / 11)$ \\
\hline Alteraçōes radiograf. carac. da AR & 0,058 & $70 \%(49 / 70)$ & $100 \%(11 / 11)$ \\
\hline $\begin{array}{l}\text { Classificação capacidade funcional } \\
\text { da AR }\end{array}$ & 0,0132 & $11 \%(8 / 70)$ & $45 \%(5 / 11)$ \\
\hline Classificação em estágios da AR & 0,025 & $44 \%(31 / 70)$ & $82 \%(9 / 11)$ \\
\hline Ranawat & 0,001 & $3 \%(270)$ & $64 \%(7 / 11)$ \\
\hline Subluxação atlanto-axial & 0,003 & $7 \%(5 / 70)$ & $45 \%(5 / 11)$ \\
\hline Erosão processo odontóide & 0,048 & $31 \%(22 / 70)$ & $64 \%(7 / 11)$ \\
\hline Estreitamento discal cervical alto & 0,043 & $36 \%(25 / 70)$ & $73 \%(8 / 11)$ \\
\hline
\end{tabular}

* Teste exato de Fisher 


\subsubsection{Subluxação atlanto-axial $\left(C_{1}-C_{2}\right)$}

Dos 81 pacientes estudados, portadores de artrite reumatóide, havia 10 pacientes com subluxação atlanto-axial (SAA). Os valores positivos da avaliação radiográfica da instabilidade $C_{1}-C_{2}$ (SAA) mostraram haver diferença significante $(p<0,05)$ (tabela 10).

Tabela 10 - Associação entre a avaliação da subluxação atlanto-axial e demais variáveis estudadas

\begin{tabular}{|c|c|c|c|}
\hline \multirow[b]{2}{*}{ Variáveis } & \multirow{2}{*}{$\begin{array}{c}\text { Valor da } \\
\text { diferença } \\
\text { significativa } \\
\text { (p)* }\end{array}$} & \multicolumn{2}{|c|}{ Subluxação atlianto-axial } \\
\hline & & $\begin{array}{l}\text { Valor ( - ) } \\
\qquad n=71\end{array}$ & $\begin{array}{c}\text { Valor }(+) \\
n=10\end{array}$ \\
\hline Perda equilíbrio & 0,033 & $32 \%(23 / 71)$ & $70 \%(7 / 10)$ \\
\hline Parestesia & 0,038 & $18 \%(13 / 71)$ & $50 \%(5 / 10)$ \\
\hline Alteração clínica nas mãos & 0,054 & $69 \%(49 / 71)$ & $100 \%(10 / 10)$ \\
\hline Alteraçōes radiográficas carac. AR & 0,056 & $70 \%(50 / 71)$ & $100 \%(10 / 10)$ \\
\hline Classificação em estágios da AR & 0,007 & $44 \%(31 / 71)$ & $90 \%(9 / 10)$ \\
\hline Ranawat & 0,011 & $7 \%(5 / 71)$ & $40 \%(4 / 10)$ \\
\hline Redlund-Johnel & 0,003 & $8 \%(6 / 71)$ & $50 \%(5 / 10)$ \\
\hline Erosão odontóide & 0,030 & $31 \%(22 / 71)$ & $70 \%(7 / 10)$ \\
\hline Fusão óssea & 0,026 & $10 \%(7 / 71)$ & $40 \%(4 / 10)$ \\
\hline
\end{tabular}

- Teste exato de Fisher 
A alteração radiográfica da subluxação atlanto-axial, quando confrontada com a variável classificação de capacidade, apresentou níveis de significância diferentes em métodos distintos, mostrando prevalência da subluxação atlanto-axial em fases mais precoces desta classificação, (tabela 11).

Tabela 11 - A disposição da presença de subluxação atlanto-axial, segundo a classificação de capacidade funcional mostrando à associação entre a avaliação de instabilidade cervical pelo método de Redlund-Johnell e diferentes variáveis estudadas.

\begin{tabular}{lrrrrr}
\hline & \multicolumn{5}{c}{ Classificação Capacidade Funcional da } \\
& & AR & \\
\cline { 2 - 6 } & & I & II & III & IV \\
\hline Subluxação & Não & 38 & 23 & 10 & 0 \\
Atlanto-axial & Sim & 0 & 7 & 1 & 2 \\
& & 38 & 30 & 11 & 2 \\
\hline Teste exato de Fisher $=0,197$ & & & &
\end{tabular}

\subsubsection{Subluxação subaxial $\left(C_{2}-C_{7}\right)$}

Dos 81 pacientes estudados, portadores de artrite reumatóide, 5 apresentavam subluxação subaxial caracterizada por deslocamento vertebral e em um só nível subaxial. Os valores positivos da 
avaliação radiográfica da subluxação subaxial mostraram diferença significante $(p<0,05)$ com as variáveis listadas na tabela 12 .

Tabela 12 - Associação entre a avaliação de instabilidade cervical subaxial e diferentes variáveis estudadas

\begin{tabular}{lccc}
\hline \multirow{2}{*}{ Variáveis } & $\begin{array}{c}\text { Valor da } \\
\text { diferença }\end{array}$ & \multicolumn{2}{c}{ Subluxação subaxial } \\
\cline { 3 - 4 } & significativa & Valor (-) & Valor (+) \\
& $(p)^{*}$ & $n=76$ & $n=5$ \\
\hline Clonus & 0,028 & $4 \%(3 / 76)$ & $40 \%(2 / 5)$ \\
Classificação capacidade & & & \\
funcional da AR & 0,027 & $13 \%(10 / 76)$ & $60 \%(3 / 5)$ \\
Classificação em estágios da AR & 0,025 & $46 \%(35 / 76)$ & $100 \%(5 / 5)$ \\
Erosão odontóide & 0,052 & $33 \%(25 / 76)$ & $80 \%(4 / 5)$ \\
Estreitamento discal cervical alto & 0,009 & $37 \%(28 / 76)$ & $100 \%(5 / 5)$ \\
Subluxação múltipla & & & \\
Esclerose superficial vertebral & 0,017 & $3 \%(2 / 76)$ & $40 \%(2 / 5)$ \\
Esclerose apófises articulares & 0,017 & $42 \%(32 / 76)$ & $100 \%(5 / 5)$ \\
Fusão óssea & 0,047 & $53 \%(40 / 76)$ & $100 \%(5 / 5)$ \\
\hline & 0,016 & $11 \%(8 / 76)$ & $60 \%(3 / 5)$ \\
\hline
\end{tabular}

- Teste exato de Fisher 


\subsubsection{Erosão do processo odontóide}

Dos 81 pacientes avaliados, 29 apresentaram erosão do odontóide. A diferença significativa entre os pacientes que apresentavam erosão do odontóide e as variáveis estudadas estão apresentadas na tabela 13.

Tabela 13 - Associação da avaliação radiográfica de erosão do processo odontóide e demais variáveis

\begin{tabular}{|c|c|c|c|}
\hline \multirow{2}{*}{ Variáveis } & \multirow{2}{*}{$\begin{array}{c}\text { Valor da } \\
\text { diferença } \\
\text { significativa } \\
\text { (p)* }\end{array}$} & \multicolumn{2}{|c|}{$\begin{array}{c}\text { Erosāo do processo } \\
\text { odontóide }\end{array}$} \\
\hline & & $\begin{array}{l}\text { Valor }(-) \\
n=52\end{array}$ & $\begin{array}{c}\text { Valor }(+) \\
n=29\end{array}$ \\
\hline Perda do equilíbrio & 0,055 & $29 \%(15 / 52)$ & $52 \%(15 / 29)$ \\
\hline Alterações clínicas da mão & 0,067 & $65 \%(34 / 52)$ & $86 \%(25 / 29)$ \\
\hline Waaler-Rose & 0,008 & $73 \%(38 / 52)$ & $97 \%(28 / 29)$ \\
\hline Classificaçāo em estágios da AR & 0,0005 & $35 \%(18 / 52)$ & $76 \%(22 / 29)$ \\
\hline Ranawat & 0,062 & $6 \%(3 / 52)$ & $21 \%(6 / 29)$ \\
\hline Redlung-Johnell & 0,048 & $8 \%(4 / 52)$ & $24 \%(7 / 29)$ \\
\hline Subluxação atlanto-axial & 0,030 & $6 \%(3 / 52)$ & $24 \%(7 / 29)$ \\
\hline Subluxação subaxial & 0,052 & $2 \%(1 / 52)$ & $14 \%(4 / 29)$ \\
\hline Estreitamento discal cervical alto & 0,004 & $29 \%(15 / 52)$ & $62 \%(18 / 29)$ \\
\hline Esclerose superficie vertebral & 0,002 & $33 \%(17 / 52)$ & $69 \%(20 / 29)$ \\
\hline Esclerose apófises articulares & 0,0004 & $40 \%(21 / 52)$ & $83 \%(24 / 29)$ \\
\hline Fusão óssea & 0,013 & $6 \%(3 / 52)$ & $28 \%(8 / 29)$ \\
\hline
\end{tabular}

- Teste exato de Fisher 


\subsubsection{Estreitamento discal cervical alto}

Dos 81 pacientes avaliados, 33 apresentatavam estreitamento discal cervical alto. A diferença significante $(p<0,05)$ presente entre os pacientes que apresentavam estreitamento discal cervical alto e as variáveis estudadas estão apresentados na tabela 14.

Tabela 14 - Valores da significância entre a variável estreitamento discal cervical alta e diferentes variáveis

\begin{tabular}{|c|c|c|c|}
\hline$y^{x}-2=0$ & $\begin{array}{l}\text { Valor da } \\
\text { diferença }\end{array}$ & $\begin{array}{r}\text { Estreitame } \\
\text { cervlc }\end{array}$ & $\begin{array}{l}\text { to discal } \\
\text { alto }\end{array}$ \\
\hline els & $\begin{array}{l}\text { significativa } \\
(\mathbf{p})^{*}\end{array}$ & $\begin{array}{c}\text { Valor }(\cdot) \\
n=48\end{array}$ & $\begin{array}{c}\text { Valor }(+) \\
n=33\end{array}$ \\
\hline Cefaléia & 0,010 & $50 \%(24 / 48)$ & $21 \%(7 / 33)$ \\
\hline $\begin{array}{l}\text { Classificação capacidade } \\
\text { funcional da AR }\end{array}$ & 0,005 & $6 \%(3 / 48)$ & $30 \%(10 / 33)$ \\
\hline Classificação em estágios da AR & 0,0001 & $31 \%(15 / 48)$ & $76 \%(25 / 33)$ \\
\hline Redlung-Johnell & 0,043 & $6 \%(3 / 48)$ & $24 \%(8 / 33)$ \\
\hline Subluxação subaxial & 0,009 & $0 \%(0 / 48)$ & $15 \%(5 / 33)$ \\
\hline Erosão do odontóide & 0,004 & $23 \%(11 / 48)$ & $55 \%(18 / 33)$ \\
\hline Subluxação múltipla & 0,024 & $0 \%(0 / 48)$ & $6 \%(2 / 33)$ \\
\hline Esclerose da superfície vertebral & 0,0001 & $21 \%(10 / 48)$ & $82 \%(27 / 33)$ \\
\hline Esclerose apófises articulares & 0,0001 & $33 \%(16 / 48)$ & $88 \%(29 / 33)$ \\
\hline Osteoporose & 0,001 & $54 \%(26 / 48)$ & $88 \%(29 / 33)$ \\
\hline Fusão óssea & 0,0003 & $2 \%(1 / 48)$ & $30 \%(10 / 33)$ \\
\hline
\end{tabular}

- Teste exato de Fisher 


\subsubsection{Subluxação múltipla}

Dos nossos 81 pacientes estudados, 41 apresentavam subluxação subaxial múltipla da coluna cervical, com deslocamento vertebral em mais de um nível subaxial. Os resultados da avaliação radiográfica da subluxação múltipla foram confrontados com as variáveis estudadas e verificado os valores de diferença significante $(p<0,05)$ (Tabela 15).

Tabela 15 - Resultado das diferenças estatísticas significantes entre a variável subluxação múltipla e variáveis estudadas

\begin{tabular}{|c|c|c|c|}
\hline \multirow{2}{*}{ Variáveis } & \multirow{2}{*}{$\begin{array}{c}\text { Valor da } \\
\text { diferença } \\
\text { significativa } \\
\text { (p) }\end{array}$} & \multicolumn{2}{|c|}{ Subluxação múltipla } \\
\hline & & $\begin{array}{c}\text { Valor }(-) \\
n=\pi\end{array}$ & $\begin{array}{c}\text { Valor }(+) \\
n=4\end{array}$ \\
\hline Classificação funcional da AR & 0,012 & $13 \%(10 / 77)$ & $75 \%(3 / 4)$ \\
\hline Classificaçāo em estágios da AR & 0,054 & $47 \%(36 / 77)$ & $100 \%(4 / 4)$ \\
\hline Subluxação subaxial & 0,017 & $3 \%(3 / 77)$ & $50 \%(2 / 4)$ \\
\hline Estreitamento discal cervical alto & 0,024 & $37 \%(29 / 77)$ & $100 \%(4 / 4)$ \\
\hline Esclerose superficie vertebral & 0,039 & $4 \%(3 / 77)$ & $100 \%(4 / 4)$ \\
\hline
\end{tabular}

"Teste exato de Fisher 


\subsubsection{Esclerose da superfície vertebral}

Dos 81 pacientes portadores de artrite reumatóide, 37 eram portadores de esclerose da superfície vertebral. Os valores da avaliação radiográfica da esclerose da superfície vertical mostraram haver diferença significante $(p<0,05)$ (Tabela 16).

Tabela 16 - Valores dos níveis de diferença significante entre a variável esclerose da superfície vertebral e diferentes variáveis

\begin{tabular}{|c|c|c|c|}
\hline \multirow{2}{*}{ Variáveis } & \multirow{2}{*}{$\begin{array}{c}\text { Valor da } \\
\text { diferença } \\
\text { significativa } \\
\text { (p) }\end{array}$} & \multicolumn{2}{|c|}{$\begin{array}{c}\text { Esclerose da superfície } \\
\text { vertebral }\end{array}$} \\
\hline & & $\begin{array}{c}\text { Valor }(-) \\
n=44\end{array}$ & $\begin{array}{c}\text { Valor }(+) \\
n=37\end{array}$ \\
\hline Cefaléia & 0,022 & $50 \%(22 / 44)$ & $24 \%(9 / 37)$ \\
\hline Fraqueza muscular & 0,024 & $43 \%(19 / 44)$ & $70 \%(26 / 37)$ \\
\hline Látex & 0,049 & $84 \%(37 / 44)$ & $97 \%(36 / 37)$ \\
\hline $\begin{array}{l}\text { Títulos anormais de fatores } \\
\text { reumatóide }\end{array}$ & 0,049 & $84 \%(37 / 44)$ & $97 \%(36 / 37)$ \\
\hline $\begin{array}{l}\text { Classificação capacidade } \\
\text { funcional }\end{array}$ & 0,016 & $7 \%(3 / 44)$ & $27 \%(10 / 37)$ \\
\hline Classificação em estágios da AR & 0,0001 & $30 \%(13 / 44)$ & $73 \%(27 / 37)$ \\
\hline Ranawat & 0,044 & $5 \%(2 / 44)$ & $19 \%(7 / 37)$ \\
\hline Subluxação subaxial & 0,017 & $0 \%(0 / 44)$ & $14 \%(5 / 37)$ \\
\hline Erosão odontóide & 0,002 & $20 \%(9 / 44)$ & $54 \%(20 / 37)$ \\
\hline Estreitamento discal cervical alto & 0,0001 & $14 \%(6 / 44)$ & $73 \%(27 / 37)$ \\
\hline Subluxação múltipla & 0,039 & $0 \%(0 / 44)$ & $11 \%(4 / 37)$ \\
\hline Esclerose apófises articulares & 0,0001 & $25 \%(11 / 44)$ & $92 \%(34 / 37)$ \\
\hline Osteoporose & 0,0003 & $50 \%(22 / 44)$ & $89 \%(33 / 37)$ \\
\hline Fusão óssea & 0,0001 & $0 \%(0 / 44)$ & $30 \%(11 / 37)$ \\
\hline
\end{tabular}

- Teste exato de Fisher 


\subsubsection{Esclerose das apófises articulares}

Dos 81 pacientes portadores de artrite reumatóide, 45 apresentavam esclerose das apófises articulares. Verificamos diferença significante entre a esclerose das apófises articulares e demais variáveis (Tabela 17).

Tabela 17 - Resultado das associações entre a variável esclerose das apófises articulares e as diferentes variáveis que apresentaram significância estatística.

\begin{tabular}{|c|c|c|c|}
\hline \multirow{2}{*}{ Variáveis } & \multirow{2}{*}{$\begin{array}{c}\text { Valor da } \\
\text { diferença } \\
\text { significativa } \\
\text { (p) }\end{array}$} & \multicolumn{2}{|c|}{$\begin{array}{c}\text { Esclerose das apófises } \\
\text { articulares }\end{array}$} \\
\hline & & $\begin{array}{c}\text { Valor }(-) \\
n=36\end{array}$ & $\begin{array}{c}\text { Valor }(+) \\
n=45\end{array}$ \\
\hline Fraqueza muscular (subjetivo) & 0,012 & $39 \%(14 / 36)$ & $69 \%(31 / 45)$ \\
\hline Perda equilíbrio & 0,0010 & $17 \%(6 / 36)$ & $53 \%(24 / 45)$ \\
\hline Parestesia & 0,035 & $11 \%(4 / 36)$ & $31 \%(14 / 45)$ \\
\hline Fraqueza muscular (objetiva) & 0,007 & $8 \%(3 / 36)$ & 15/45) \\
\hline Alterações clínicas nas mãos & 0,002 & $56 \%(20 / 36)$ & $87 \%(39 / 45)$ \\
\hline Alteração radiográfica carac. da & 0,005 & $58 \%(21 / 36)$ & $87 \%(39 / 45)$ \\
\hline & & & \\
\hline $\begin{array}{l}\text { Classificação capacidade } \\
\text { funcional da AR }\end{array}$ & 0,0001 & $3 \%(1 / 36)$ & $27 \%(12 / 45)$ \\
\hline Classificação em estágios da AR & 0,0001 & $25 \%(9 / 36)$ & $69 \%(31 / 45)$ \\
\hline Ranawat & 0,038 & $3 \%(1 / 36)$ & $8 / 45)$ \\
\hline Erosão odontóide & 0,0004 & $14 \%(5 / 36)$ & $53 \%(24 / 45)$ \\
\hline Estreitamento discal cervical alto & 0,0001 & $11 \%(4 / 36)$ & $64 \%(29 / 45)$ \\
\hline Esclerose superfície vertebral & 0,0001 & $11 \%(4 / 36)$ & $64 \%(29 / 45)$ \\
\hline Osteoporose & 0,0001 & $44 \%(16 / 36)$ & $87 \%(39 / 45)$ \\
\hline Fusão óssea & 0,0008 & $0 \%(0 / 36)$ & $24 \%(11 / 45)$ \\
\hline
\end{tabular}

" Teste exato de Fisher 


\subsubsection{Osteoporose}

Dos 81 pacientes portadores de artrite reumatóide, 55 apresentavam osteoporose. Os valores da diferença significante $(p<0,05)$ foram estudados entre os pacientes portadores de artrite reumatóide e as variáveis citadas (Tabela 18).

Tabela 18- Resultado dos valores estatisticamente significantes da avaliação radiográfica de osteoporose e das demais variáveis estudadas

\begin{tabular}{|c|c|c|c|}
\hline \multirow{2}{*}{ Variáveis } & \multirow{2}{*}{$\begin{array}{c}\text { Valor da } \\
\text { diferença } \\
\text { significativa } \\
\text { (p)* }\end{array}$} & \multicolumn{2}{|c|}{ Osteoporose } \\
\hline & & $\begin{array}{c}\text { Valor }(-) \\
n=26\end{array}$ & $\begin{array}{c}\text { Valor }(+) \\
n=55\end{array}$ \\
\hline Perda de equilíbrio & 0,0012 & $12 \%(3 / 26)$ & $49 \%(27 / 55)$ \\
\hline Parestesia & 0,043 & $8 \%(2 / 26)$ & $29 \%(16 / 55)$ \\
\hline Alteração reflexo & 0,0004 & $8 \%(2 / 26)$ & $47 \%(26 / 55)$ \\
\hline Fraqueza muscular (objetiva) & 0,043 & $8 \%(2 / 26)$ & $29 \%(16 / 55)$ \\
\hline Alterações clínicas das mãos & 0,014 & $54 \%(14 / 26)$ & $82 \%(45 / 55)$ \\
\hline $\begin{array}{l}\text { Alterações radiográficas } \\
\text { características da AR }\end{array}$ & 0,0002 & $46 \%(12 / 26)$ & $87 \%(48 / 55)$ \\
\hline $\begin{array}{l}\text { Classificação da capacidade } \\
\text { funcional da AR }\end{array}$ & 0,052 & $46 \%(1 / 26)$ & $22 \%(12 / 55)$ \\
\hline Classificação em estágios da AR & 0,0001 & $15 \%(4 / 26)$ & $65 \%(36 / 55)$ \\
\hline Fusão óssea & 0,013 & $0 \%(0 / 26)$ & $20 \%(11 / 55)$ \\
\hline
\end{tabular}

"Teste exato de Fisher 


\subsubsection{Fusão óssea}

Dos 81 pacientes portadores de artrite reumatóide, 11 apresentavam fusão óssea entre um ou mais corpos vertebrais .A associação desta alteração radiográfica com as demais variáveis foi considerada uma diferença significativa $(p<0,05)$ (Tabela 19).

Tabela 19 - Resultado das diferenças significantes dos pacientes portadores de fusão óssea e das variáveis estudadas

\begin{tabular}{lccc}
\hline \multicolumn{1}{c}{ Variáveis } & Valor da & \multicolumn{2}{c}{ Fusão óssea } \\
& diferença & & \\
\cline { 3 - 4 } & significativa & Valor $(-)$ & Valor (+) \\
& $(p)^{*}$ & $n=70$ & $n=11$ \\
\hline Rigidez cervical & 0,007 & $21 \%(15 / 70)$ & $64 \%(7 / 11)$ \\
Reflexos alterados & 0,0008 & $27 \%(19 / 70)$ & $82 \%(9 / 11)$ \\
Fraqueza muscular (objetiva) & 0,012 & $17 \%(12 / 70)$ & $55 \%(6 / 11)$ \\
Classificação da capacidade & & & \\
funcional da AR & 0,013 & $11 \%(8 / 70)$ & $45 \%(5 / 11)$ \\
Classificação em estágios da AR & 0,025 & $44 \%(31 / 70)$ & $82 \%(9 / 11)$ \\
\hline
\end{tabular}

Teste exato de Fisher 
As alterações radiográficas da coluna cervical foram confrontadas e foi observada a prevalência aumentada da instabilidade nas classes mais avançadas da classificação de capacidade funcional de artrite reumatóide (Tabela 20).

Tabela 20 - Número de pacientes que apresentaram alterações das variáveis estudadas e percentual, quando confrontadas com os graus da classificação da capacidade funcional de artrite reumatóide.

\begin{tabular}{ccccccc}
\hline Classes & Casos & Ranawat & $\begin{array}{c}\text { Redlund- } \\
\text { Johnell }\end{array}$ & $\begin{array}{c}\text { C1-C2 } \\
+ \text { C1-C2 }\end{array}$ & + C1-C2 \\
\hline I & 38 & $0(0 \%)$ & $2(5 \%)$ & $0(0 \%)$ & $0(0 \%)$ & $0(0 \%)$ \\
II & 30 & $2(7 \%)$ & $4(13 \%)$ & $7(23 \%)$ & $1(3 \%)$ & $2(7 \%)$ \\
III & 11 & $5(45 \%)$ & $3(27 \%)$ & $1(9 \%)$ & $1(9 \%)$ & $1(9 \%)$ \\
IV & 2 & $2(100 \%)$ & $2(100 \%)$ & $2(100 \%)$ & $2(100 \%)$ & $2(100 \%)$ \\
\hline Total & 81 & 9 & 11 & 10 & 4 & 5 \\
\hline
\end{tabular}

As variáveis das demais alterações da coluna cervical, quando dispostas segundo a classificação da capacidade funcional da artrite reumatóide demonstram que a prevalência das lesões acentuam-se também em classes mais elevadas (Tabela 21). 
Tabela 21 - Número de pacientes que apresentaram alterações da variável radiográfica, segundo a classificação de capacidade funcional da artrite reumatóide (ACR).

\begin{tabular}{|c|c|c|c|c|c|c|c|}
\hline Classes & $\begin{array}{l}\text { Subluxaçã } \\
\text { o subaxial }\end{array}$ & $\begin{array}{l}\text { subluxação } \\
\text { múltipla }\end{array}$ & $\begin{array}{c}\text { Esclerose } \\
\text { da } \\
\text { superficie } \\
\text { vertebral }\end{array}$ & $\begin{array}{c}\text { Esclerose } \\
\text { das } \\
\text { apófises } \\
\text { articulares }\end{array}$ & $\begin{array}{c}\text { Estreitamento } \\
\text { discal cervical } \\
\text { alto }\end{array}$ & $\begin{array}{l}\text { Osteopo- } \\
\text { rose }\end{array}$ & $\begin{array}{l}\text { Fusāo } \\
\text { ossea }\end{array}$ \\
\hline I $(n=38)$ & 1 & 0 & 11 & 13 & 10 & 17 & 0 \\
\hline$\|(n=30)$ & 1 & 1 & 16 & 20 & 13 & 26 & 6 \\
\hline III $(n=11)$ & 2 & 2 & 8 & 10 & 8 & 10 & 3 \\
\hline IV ( $n=02)$ & 1 & 1 & 2 & 2 & 2 & 2 & 2 \\
\hline $\begin{array}{c}\text { Total } \\
(n=81)\end{array}$ & 5 & 4 & 37 & 45 & 33 & 55 & 11 \\
\hline
\end{tabular}

A classificação em estágios da artrite reumatóide foi confrontada com as demais alterações radiográficas da coluna cervical e observa-se o aumento da prevalência destas nos estágios mais avançados da classificação (Tabela 22).

Tabela 22 - Número de pacientes que apresentaram alterações da variável radiográfica, segundo a classificação em estágios da AR.

\begin{tabular}{|c|c|c|c|c|c|c|c|}
\hline Estágio & $\begin{array}{c}\text { Subluxação } \\
\text { subaxial }\end{array}$ & $\begin{array}{l}\text { Erosāo do } \\
\text { odontóide }\end{array}$ & $\begin{array}{c}\text { Esclerose } \\
\text { da } \\
\text { superficio } \\
\text { vertebral }\end{array}$ & $\begin{array}{c}\text { Esclerose } \\
\text { das } \\
\text { apófises } \\
\text { articulares }\end{array}$ & $\begin{array}{c}\text { Estreitamento } \\
\text { discal cervical } \\
\text { alto }\end{array}$ & $\begin{array}{c}\text { Osteoporo } \\
\text { se }\end{array}$ & $\begin{array}{l}\text { Fusão } \\
\text { óssea }\end{array}$ \\
\hline$I(n=17)$ & 0 & 2 & 4 & 4 & 3 & 4 & 0 \\
\hline II $(n=24)$ & 0 & 5 & 6 & 10 & 5 & 15 & 2 \\
\hline III $(n=34)$ & 3 & 16 & 21 & 25 & 19 & 30 & 5 \\
\hline IV $(n=6)$ & 2 & 6 & 6 & 6 & 6 & 6 & 4 \\
\hline $\begin{array}{c}\text { Total } \\
(n=81)\end{array}$ & 5 & 29 & 37 & 45 & 33 & 55 & 11 \\
\hline
\end{tabular}




\section{DISCUSSÃO}

A coluna cervical está freqüentemente afetada nos pacientes que apresentam artrite reumatóide, cuja fisiopatologia, manifestação clínica e radiográfica já foram anteriormente mencionadas e discutidas. O envolvimento da coluna cervical na artrite reumatóide é descrito numa incidência que varia de 17 a $86 \%$ dos pacientes, considerando-se todos os pacientes (SHARP et al.,1958; CONLON et al., 1966; MEIKLE \& WILKSON, 1971; SMITH et al., 1972; CABOT \& BECKER, 1978). Em nosso meio, existe uma carência de estudos abordando esse assunto, e os únicos trabalhos encontrados foram realizados por BARROS FILHO et al. $(1989,1990,1992)$. Esse fato foi a grande motivação para realizarmos esse estudo que aborda a incidência de alterações clínicas e radiográficas em pacientes portadores de artrite reumatóide, bem como a associação entre os sinais clínicos da doença e os sinais radiográficos das alterações e instabilidade da coluna cervical, que possivelmente é inédito em nosso meio.

Através da metodologia empregada no presente estudo, procuramos associar, por meio de análise estatística, os achados clínicos e radiográficos de uma população de pacientes portadores de artrite reumatóide, que eram acompanhados rotineiramente no Ambulatório de Imunologia do HCRP. Esses pacientes foram aleatoriamente incluídos nos estudo, com o objetivo de observarmos a ocorrência das alterações da 
coluna cervical numa população ambulatorial de pacientes com artrite reumatóide.

Na avaliação clínica dos pacientes, consideramos diversas variáveis clínicas, selecionadas com a finalidade de associá-las às alterações radiográficas da coluna cervical, e foram também utilizados os critérios de classificação de capacidade funcional de artrite reumatóide (ACR), revisada por ARNETT et al. (1988), e a classificação em estágios da artrite reumatóide, ambas com a finalidade de situar esses pacientes no espectro de gravidade da doença, pois consideramos de grande importância a avaliação do grau de gravidade da doença no momento em que estamos estudando a presença de instabilidade da coluna cervical.

Segundo a avaliação radiográfica consideramos os diferentes segmentos da coluna cervical, tomando-se como base as várias alterações já conhecidas que ocorrem na coluna cervical de pacientes portadores de artrite reumatóide. Cada tipo de alteração foi isoladamente avaliado por meio do estudo de medidas específicas, cujos valores e método da realização das suas medidas já estão bem definidos e aceitos na prática clínica.

A determinação da instabilidade ao nivel do occipital e do atlas apresenta algumas dificuldades e limitações, resultantes da destruição e erosão do tecido ósseo, que estão presentes na artrite reumatóide. No início de nossa mensuração radiográfica utilizamos os métodos de McGregor, linha de Chamberlain, linha de McRae, método de RedlundJohnell e método de Ranawat, mas devido às dificuldades encontradas, 
fomos obrigados a abandonar a utilização do método de McGregor, da linha de Chamberlain e da linha de McRae. MORIZONO, SAKOU, KAWAIDA (1987) e BARROS FILHO et al. $(1990,1992)$ relataram que as medidas obtidas por esses métodos eram imprecisas e não adequadas para o diagnóstico da instabilidade occipito-cervical da artrite reumatóide, tendo recomendado a utilização do método de Redlund-Johnell e Ranawat para a determinação dessa instabilidade e, segundo nossos resultados durante as mensurações radiográficas, acreditamos que esses dois métodos sejam realmente os mais adequados para essa finalidade.

O estudo da instabilidade da coluna cervical na artrite reumatóide, por meio de radiografias dinâmicas, ainda é um bom método. KAWAIDA et al. (1989), em estudo de 55 pacientes portadores de artrite reumatóide que apresentavam sinais radiográficos de instabilidade cervical, observaram que a comparação dos resultados obtidos pelos exames radiográficos e de ressonância magnética eram muito semelhantes, e concluíram que a compressão da medula espinhal pode ser estimada pelos valores fornecidos pelo estudo radiográfico convencional, utilizando-se radiografias dinâmicas em perfil. As radiografias dinâmicas em perfil da coluna cervical podem continuar, na opinião de alguns autores (BRAUNSTEIN et al., 1984; TOOLANEN, LARSSON, FAGERLUNG, 1986; BODEN, 1994; DREYER \& BODEN, 1999) como método primário para a avaliação dos pacientes com artrite reumatóide, e na presença de comprometimento neurológico a tomografia computadorizada, ou mais recentemente a ressonância magnética estariam então indicadas. A 
ressonância magnética estaria ainda especialmente indicada nos pacientes portadores de déficit neurológico e sem alterações radiográficas significativas (BREEDVELD et al., 1987), com a finalidade de fornecer informações acerca da influência dos tecidos moles (pannus por exemplo) na compressão das estruturas nervosas (KAWAIDA et al., 1989b). Mielopatia em pacientes com leve subluxação foi descrita como consequência da compressão do tecido nervoso pelo pannus retrodental (STEVENS, KENDALL, CROCKARD, 1986). A ressonância magnética apesar de possuir imagem superior e demonstrar a compressão da medula espinhal e o pannus sinovial, ainda é considerada como procedimento que demanda muito tempo e custos elevados para ser realizada como rotina no rastreamento de instabilidade cervical de pacientes portadores de artrite reumatóide (BODEN, 1994; DREYER \& BODEN, 1999). Acreditamos que o recurso das radiografias em perfil cervical, como meio diagnóstico de anormalidades na coluna cervical, constitui um método seguro e um custo de cerca de 5 a $8 \%$ do valor de uma ressonância magnética. Os métodos para avaliação de instabilidades occipito- $C_{1}, C_{1}-C_{2}$, e subaxiais, obtidas através de radiografias simples contribuem para um rastreamento primário destas lesões.

O estudo estatístico mostrou que não houve diferença significante entre os sintomas estudados (cervicalgia e dor occiptal) e a presença de alterações radiográficas na coluna cervical (migração superior do processo odontóide, subluxação atlanto-axial, subluxação subaxial, erosão do processo odontóide, estreitamento discal, 
subluxação múltipla, esclerose da superfície vertebral, esclerose das apófises articulares, osteoporose e fusão óssea). Ao contrário do que é relatado em outros trabalhos que valorizam a presença desses sintomas (PELLICl et al., 1981; LIPSON, 1989; KAWAIDA et al. 1989a; KAWAIDA et al., 1989b; BODEN, 1994), esta observação é de grande importância, pois em nosso estudo encontramos pacientes que apresentavam sinais radiográficos de instabilidade cervical e encontravam-se assintomáticos. CABOT \& BECKER (1978) também relataram essa dissociação entre sintomas e achados radiográficos em pacientes com artrite reumatóide, tendo recomendado a realização prévia e de rotina de exames radiográficos para a coluna cervical naqueles pacientes a serem submetidos à anestesia geral.

KAWAIDA et al. (1989b) observaram que a dor cervical e occipital eram os sintomas mais freqüentes na série de pacientes que estudaram. Os autores observaram esses sintomas em $100 \%$ dos pacientes que apresentavam valores anormais da linha de Redlund-Johnell, em $84 \%$ dos pacientes que apresentavam valores anormais da linha de Ranawat e em $72 \%$ dos que apresentavam subluxação atlanto-axial. Na série estudada por MENEZES et al. (1985), a dor occipital ocorreu em $45 \%$ dos pacientes que apresentavam migração superior do odontóide.

PELLICCI et al. (1981) observaram a cervicalgia como o sintoma mais freqüente nos pacientes que apresentavam instabilidade occipito-cervical, porém, esses autores notaram que $50 \%$ dos pacientes assintomáticos apresentavam subluxação cervical. WINFIELD et al. (1981), 
COLLINS et al. (1991) relataram que muitos pacientes portadores de subluxação atlanto-axial eram assintomáticos, e esses relatos corroboram à nossa observação, quando notamos $50 \%$ dos pacientes assintomáticos com algum tipo de instabilidade cervical (subluxação); acreditamos que a ausência de sintomas não invalida a pesquisa de instabilidade. Essa observação é de grande importância, pois é freqüente esta pesquisa na presença de sintomas, não sendo verdadeiro o contrário.

Os sintomas clínicos estudados, tais como, vertigem, cefaléia, tontura, distúrbios visuais, rigidez cervical, dor occipital, espasmo muscular, fraqueza muscular subjetiva, adormecimento dos membros, sensação de crepitação, parestesia e presença de clonus estão presentes no quadro clínico dos pacientes portadores de artrite reumatóide, porém os mesmos não apresentaram diferença significante com as instabilidades na coluna cervical, consideração importante na análise clínica da evolução da artrite reumatóide, na qual os pacientes devem ser submetidos, de rotina, a um estudo radiográfico criterioso. Isto posto, esses sinais e sintomas não serviriam como indicativos da presença de instabilidade da coluna cervical.

A avaliação neurológica dos pacientes com artrite reumatóide grave é problemática e de difícil realização devido à destruição das articulações periféricas ocasionada pela doença, a qual interfere na avaliação motora dos membros superiores e inferiores (RANA, 1989; BODEN et al., 1993; BODEN, 1994; DELAMARTER \& BOHLMAN, 1994). A rigidez e a dor articular afetam os reflexos de estiramento e tornam o exame 
impreciso. As neuropatias periféricas podem ocorrer devido à compressão pela hipertrofia sinovial, ou ainda como resultado de endarterite (FLOYD et al., 1989). DELAMARTER \& BOHLMAN (1994) sugerem, em estudo baseado em necropsias de pacientes com artrite reumatóide, que a paralisia na artrite reumatóide poderia ocorrer devido a problemas mecânicos de compressão e/ou à lesão vascular intrínseca. Insuficiência vértebro-basilar, quando associada à migração superior do odontóide, pode causar tinido, vertigem, perda de equilíbrio, distúrbios visuais, diplopia e disfagia, mas as alterações do exame físico podem ser mascaradas pelas alterações articulares periféricas da doença, que resultam em fraqueza, tenosinovite, rotura tendinosa e atrofia muscular (KAWAIDA et al., 1989a,b; BODEN, 1994).

A associação da variável clonus com subluxação subaxial apresentou diferença significativa $(p=0,028)$. Dentre os 5 pacientes nos quais observamos instabilidade descrita, 2 apresentavam clonus, possivelmente relacionado ao diâmetro do canal vertebral anatomicamente mais estreito nesse nivel, ao contrário do nível occipito- $C_{2}$ que apresenta canal mais largo, por conta de uma reserva anátomo-funcional, considerando-se que não houve associação entre as variáveis migração superior do odontóide e subluxação atlanto-axial com a variável clonus em nosso estudo. DELAMARTER \& BOHLMAN (1994) demonstraram que o diâmetro do canal vertebral no nível de $C_{1}-C_{2}$ é maior, existindo área de segurança entre as estruturas ósseas e nervosas de $13 \mathrm{~mm}$ e no segmento subaxial essa área de segurança era de $8 \mathrm{~mm}$. 
FLOYD et al. (1989) não observaram diferença significativa das alterações neurológicas entre os pacientes que apresentavam instabilidade cervical e aqueles cujas colunas eram estáveis. Esses autores acreditam que as alterações neurológicas não indicam necessariamente a compressão dos tecidos nervosos, mas podem, com maior probabilidade, refletir a disseminação do envolvimento mesenquimal da doença.

Estudos têm demonstrado (MATHEWS, 1969; RANA, 1989) a tênue associação entre os achados radiográficos demonstrando subluxação atlanto-axial e alterações neurológicas. A presença de sinais neurológicos não serviriam para a indicação do tratamento cirúrgico e as alterações neurológicas isoladas são de difícil interpretação e podem ocasionar enganos na sua indicação.

Em nosso grupo de pacientes estudados, a avaliação da presença de clonus corrobora a opinião de alguns autores (FLOYD et al., 1989; BODEN et al., 1993; BODEN, 1994), pois observamos a sua presença na ausência de instabilidade da coluna cervical, sugerindo que a compressão medular não ocorreria exclusivamente devido a fatores mecânicos de compressão da estruturas nervosas.

A presença de instabilidade da coluna cervical não está associada exclusivamente à presença de alterações neurológicas (COLLINS et al., 1991; KRAMER et al., 1991), e concordamos com essa afirmação baseados na observação feita no grupo de pacientes por nós estudado. $\mathrm{Na}$ análise das alterações neurológicas devem ainda ser considerados outros fatores, que possuem grande influência no aparecimento dessas alterações, 
como é o caso do diâmetro do canal vertebral (DELAMARTER \& BOHLMAN, 1994), a proliferação do tecido sinovial (EULDERINK \& MEIJERS, 1976; CABOT \& BECKER, 1978; KRAMER et al., 1991) e vasculites (ZEIDMAN \& DUCKER, 1994).

Em nosso estudo, os achados radiográficos de subluxação atlanto-axial e migração superior do odontóide não foram associados à avaliação neurológica, em concordância com alguns autores (FLOYD et al., 1989; KAWAIDA et al., 1989a,b; COLLINS et al., 1991; GROB, 1993; ODA et al., 1995). MATHEWS (1969) demonstrou que $1 / 3$ dos pacientes com subluxação atlanto-axial desenvolveram sinais neurológicos relacionados aos de longo trato. PELLICl et al. (1981) relataram que $36 \%$ dos pacientes com subluxação em níveis múltiplos apresentavam sinais neurológicos progressivos. No entanto RANA (1989) relata que a subluxação atlantoaxial ocorre usualmente de modo assintomático ou acompanhada de discretos sinais e alterações neurológicas. KRAMER et al. (1991) relataram que a subluxação atlanto-axial poderia ser grave e os sintomas neurológicos estariam ausentes, mesmo naqueles casos com subluxação maior que 10mm. DELAMARTER \& BOHLMAN (1994) demonstraram que no nivel $\mathrm{C}_{1-}$ $C_{2}$ existe um espaço de $13 \mathrm{~mm}$ entre as estruturas ósseas e nervosas. Em nosso estudo não observamos diferença significante entre a subluxação atlanto-axial e os sinais neurológicos.

RANA (1989) mencionou que o grau de subluxação atlantoaxial tem como característica a falta de relação direta com os sinais e sintomas, e refletiria a variação de tolerância do tecido nervoso ao trauma 
repetido. No entanto esses pacientes, ao efetuarem movimentos de flexão da coluna cervical, poderiam apresentar alguns sinais neurológicos intermitentes como vertigens, perda de destreza e distúrbios da marcha. Existe certamente discrepância entre a ausência e a gravidade de sintomas neurológicos nas subluxações atlanto-axiais, possivelmente relacionados aos diferentes diâmetros do canal vertebral (DELAMARTER \& BOHLMAN, 1994) ou mesmo à presença de erosão óssea que alargaria esse canal, a erosão apical do processo odontóide preveniria a compressão do tronco cerebral durante a progressão da migração superior do odontóide, e ainda pela acomodação das estruturas neurais em estudos de necropsias observado por EULDERINK \& MEIJERS (1976).

Têm sido descrito casos de morte súbita por envolvimento da coluna cervical em pacientes com artrite reumatóide na qual o deslocamento vertebral provocaria a compressão nervosa (MEIJERS et al., 1974). MIKULOWSKI et al. (1975) e YASZEMSKI \& SHEPLER (1990) relataram casos de morte súbita por compressão medular associada com subluxação atlanto-axial.

A associação entre os exames laboratoriais e as variáveis radiográficas de avaliação da instabilidade da coluna cervical não revelou valores estatisticamente significativos. CABOT \& BECKER (1978) relataram que a presença de nódulos subcutâneos, velocidade de hemossedimentação e prova látex não apresentavam diferença significante com a luxação atlanto-axial, estando essa observação de acordo com os resultados obtidos em nosso estudo. 
A diferença significante entre as deformidades da mão e em parte das variáveis radiográficas estudadas (linha de Redlund-Johnell, estreitamento discal alto) encontram apoio nos relatos de vários autores (BALL \& SHARP, 1971; MARTEL, 1977; LIPSON, 1984), que acreditam que as deformidades das mãos e a presença de lesões erosivas e mutilantes da cartilagem articular estejam relacionadas à progressão da doença e à instabilidade que dela resulta. Essa observação demonstra o caráter sistêmico da doença, uma vez que ocorre maior agressão do tecido sinovial periférico; aqueles tecidos localizados no segmento cervical estariam envolvidos do mesmo modo.

A ausência de diferença significante entre a variável alterações radiográficas características da artrite reumatóide nas mãos e as variáveis radiográficas estudadas na coluna cervical deve ser interpretada com certa cautela, pois ocorreram algumas associações significativas $(p<0,05)$ com o método de Redlund-Johnell, subluxação atlanto-axial $\left(C_{1}-C_{2}\right)$ e osteoporose, enquanto que as demais variáveis radiográficas, apesar de não apresentarem diferença significativa, apresentaram valores muito próximos a uma significância estatística $(p<0,05)$. Dessa forma as lesões periféricas estão em conformidade com o desenvolvimento das alterações da coluna cervical na artrite reumatóide.

As associações entre a classificação da capacidade funcional e a classificação em estágios da artrite com as diferentes variáveis radiográficas estudadas apresentaram resultados que foram bastante significativos, e com valores muito baixos na análise estatística. Esses 
achados relacionaram-se diretamente com a evolução da doença, tendo sido observado alterações mais intensas da coluna cervical naqueles pacientes que apresentavam a doença articular periférica em fases mais avançada na evolução da doença (KRAMER et al., 1991).

A análise da prevalência das instabilidades occipto-cervicais mostrou que a migração superior do odontóide ocorreu isoladamente em 11 pacientes (13,5\%) segundo a avaliação pelo método de Redlund-Johnell e em 9 pacientes (11\%) pelo método de Ranawat. Avaliada a somatória pelos dois métodos foi observada a presença da migração superior do odontóide em 13 pacientes (16\%), e 7 apresentavam essa instabilidade comum aos dois métodos. As prevalências (Tabela 7) observadas no grupo de pacientes estudados encontram-se abaixo daquelas citadas pela literatura (CABOT \& BECKER, 1978; WEISSMAN et al., 1982; LIPSON, 1984; KAWAIDA et al., 1989a; KRAMER et al., 1991; BARROS et al., 1992). Esse fato está provavelmente relacionado à quantidade de casos agrupados nas classes da classificação funcional da doença, e a maioria de nossos pacientes enquadravam-se em classes menos avançadas, explicando desse modo a menor percentagem observada dessas variáveis estudadas, porém observou-se proporcionalmente que havia um aumento acentuado de instabilidade nas classes mais avançados como mencionado na literatura (CABOT \& BECKER, 1978; WEISMANN et al., 1982). A associação significativa entre as classes da classificação de capacidade funcional da AR e a presença de migração superior do odontóide revela que houve uma predominância desta instabilidade com aumento proporcional na progressão 
destas classes. Os métodos usados na avaliação da migração superior do odontóide possuem diferentes significados; o método proposto por Ranawat reflete lesão ao nível de $C_{1}-C_{2}$ e o método de Redlund-Johnell reflete lesão ao nível do occipital- $\mathrm{C}_{2}$ que é expressada por uma redução da distância de todo o segmento desde a base do crânio até a margem inferior de $\mathrm{C}_{2}$ (MORIZONO et al.,1987; KRAMER et al., 1991). A associação desses dois métodos possibilita a obtenção de resultados mais apurados. Esses meios de mensuração também são preconizados por KAWAIDA et al. (1989a, 1989b), e acreditamos que esses dados corroboram os nossos resultados, que ao associarmos estatisticamente os resultados do método de Ranawat e Redlund-Johnell, encontramos diferença significativa $(p=0,0001)$.

Em nosso estudo, ao associarmos os resultados do método de Ranawat com os resultados da subluxação subaxial $C_{2}-C_{7}$, não encontramos diferenças significativas $(p=0,09)$. Obtivemos uma freqüência de 5 pacientes com subluxação subaxial $\mathrm{C}_{2}-\mathrm{C}_{7}$, dos quais somente 2 apresentavam-se com as variáveis do método de Ranawat alterados.

A diferença significante entre os valores obtidos pelo método de avaliação de Ranawat e Redlund-Johnnell, com os valores da subluxação atlanto-axial foram examinados, e na associação entre o valor do método de Redlund-Johnell e os valores da subluxação da articulação atlanto-axial foi observado um resultado bastante significativo $(p=0,003)$, $\theta$ o método de Ranawat com a subluxação atlanto-axial mostrou uma associação significativa $(p=0,011)$. KAWAIDA et al. (1989) mostraram também haver associação entre os métodos, em concordância com nosso estudo. 
$\mathrm{Na}$ avaliação dos nossos resultados a presença de subluxação atlanto-axial predominou em classes menos avançadas na classificação de capacidade funcional da AR, sugerindo que a subluxação aparece em períodos mais precoces da artrite reumatóide. WINFIELD et al. (1981) relataram que a subluxação atlanto-axial é uma complicação precoce na evolução da artrite reumatóide, demonstrando que $80 \%$ dos pacientes desenvolveram essa subluxação em um período de 2 anos desde a apresentação da doença e os restante $20 \%$ durante o período de 5 anos.

Observamos que a maioria das subluxações atlanto-axiais associadas à migração superior do odontóide estavam nas fases mais avançadas. WEISSMAN et al. (1982) demonstraram que a migração superior do odontóide estava usualmente acompanhada de subluxação atlanto-axial. MATHEWS (1969), SMITH et al. (1972), PELLICI et al. (1981); ODA et al. (1995) noticiaram que a redução da subluxação atlanto-axial corresponderia ao início da progressão da migração superior do odontóide. ODA et al. (1995) afirmaram que a alteração inicial da coluna cervical alta é a subluxação atlanto-axial, seguida de uma alteração adicional que era o desenvolvimento da migração superior do odontóide, que com o passar do tempo torna a subluxação atlanto-axial irredutivel. A progressão da migração superior do odontóide e do atlas foi também observado por outros autores (MATHEWS, 1969; PELLICl et al., 1981; RANA, 1989; WEISSMAN et al., 1982). PELLICl et al. (1981) no entanto, alertaram que a progressão ascendente do processo odontóide pode incorretamente apresentar-se como uma estabilização da subluxação atlanto-axial, já que o processo 
odontóide pode migrar superiormente devido à erosão atlanto-axial, e desse modo, aumenta-se a base em relação ao arco de $C_{1}$, aproximando-se 0 processo odontóide do arco de $\mathrm{C}_{1}$, aparentando a redução da subluxação, que de outra forma deve ser interpretado como uma evolução mais deletéria da migração superior do odontóide. Contrariando essas observações, BALL \& SHARP (1971) observaram a presença de 3 casos em 12 pacientes portadores de subluxação atlanto-axial, nos quais o deslocamento havia sido estabilizado pela presença de anquilose óssea nas articulações atlantoaxiais laterais. Do mesmo modo, EULDERINK \& MEIJERS (1976) detectaram a presença de 2 casos de fixação em 12 pacientes portadores de subluxação atlanto-axial, avaliados durante a necropsia de 44 pacientes adultos portadores de artrite reumatóide.

Ao associarmos estatisticamente os valores da variável do método de Ranawat e Redlund-Johnell com os valores da subluxação subaxial, e ainda com os valores da subluxação subaxial múltipla separadamente, não encontramos correlação. $O$ envolvimento da coluna cervical baixa é devido à destruição das facetas articulares, ligamentos interespinhosos e da junção disco-vertebral, e a sua patogenese não está bem esclarecida (O'HARA et al., 1991). Acredita-se que as alterações discais sejam uma extensão do processo inflamatório presente nas articulações sinoviais adjacentes, ou conseqüência da artrite das facetas articulares e frouxidão ligamentar resultante do traumatismo $\theta$ instabilidade crônica (EULDERINK \& MEIJERS, 1976). A subluxação da coluna cervical baixa ocorre mais tardiamente e aparece como deformidade isolada, fato 
que possivelmente explicaria a ausência de associação estatisticamente significante entre essa alteração e as alterações da coluna cervical alta que observamos.

Os valores das variáveis, esclerose das apófises articulares, osteoporose e a fusão óssea se associaram estatisticamente com os valores do método de Ranawat, o mesmo não acontecendo com o valores do método de Redlund-Johnell. MORIZONO et al. (1987) sugerem que o método de Ranawat esteja relacionado com a presença de formas mais graves da artrite reumatóide. Este dado possivelmente sugere a associação das lesões destrutivas que encontramos com as variáveis de mensuração da migração superior do odontóide, pelo lado da sensibilidade do método.

Com a presença das alterações destrutivas da coluna cervical subaxial mais marcantes nas fases mais graves da artrite reumatóide, observamos que essas lesões não se associaram estatisticamente com a subluxação atlanto-axial, o que em nossa análise, por inferência sugere que a subluxação atlanto-axial apresenta-se como a mais inicial das instabilidades na artrite reumatóide (EULDERINK \& MEIJERS, 1976; WINFIELD et al., 1981; BRAUNSTEIN et al., 1984; RANA, 1989; ODA et al., 1995).

A presença de associação significativa entre a variável subluxação atlanto-axial e a variável erosão do processo odontóide demonstra que as mesmas lesões que agridem os ligamentos transverso $\theta$ apical, produzem instabilidade da articulação atlanto-axial com a formação de pannus, e provocariam ao mesmo tempo a erosão do odontóide 
(EULDERINK \& MEIJERS, 1976; WINFIELD et al., 1981; DELAMARTER \& BOHLMAN, 1994; GROB et al., 1997). Em nosso estudo, cerca de $70 \%$ dos portadores de subluxação atlanto-axial apresentaram lesões características de erosão do odontóide. No entanto WINFIELD et al. (1981) relataram a presença de $33 \%$ de erosões marcadas do processo odontóide nos pacientes portadores de subluxação atlanto-axial. Verificamos, em nossa avaliação, que a erosão do odontóide estava presente em $35 \%$ de todos os pacientes portadores de artrite reumatóide. CABOT \& BECKER (1978) relataram essa freqüência em $43 \%$ dos pacientes estudados e MARTEL (1977) em 33\% deles.

KRAMER et al. (1991) relataram que a erosão do processo odontóide pode ser multifocal, apresentando-se anteriormente ao nível da sinovial entre $\circ$ arco de $C_{1}$ e $\circ$ processo odontóide, posteriormente em relação ao ligamento transverso e a bursa que se interpõe, e superiormente pela inserção do ligamento apical. Nos casos de erosão acentuada existe a possibilidade de ocorrência da fratura do processo odontóide em traumas mínimos (KRAMER et al., 1991; GROB, 1993). Nessas situações podem estar associadas mais raramente com os casos de subluxação atlanto-axial posterior, que corresponde a cerca de $6,7 \%$ de todas as subluxações atlanto-axiais (WEISSMAN et al., 1982), a qual raramente desenvolve compressão neurológica significativa (CABOT \& BECKER, 1978; WEISSMAN et al., 1982; LIPSON, 1985). Em nosso estudo não observamos casos de subluxação posterior $\mathrm{C}_{1}-\mathrm{C}_{2}$. 
Segundo WINFIELD et al. (1981), existe uma correlação entre a subluxação atlanto-axial e esclerose das apófises articulares em níveis múltiplos, mas não observamos diferença significante em nosso estudo, apesar de $50 \%$ dos pacientes com subluxação atlanto-axial apresentarem esclerose da superfície vertebral e $60 \%$ com esclerose das apófises articulares. Ao mesmo tempo, observamos que a frequência era similar em um grupo com subluxação atlanto-axial e esclerose e no outro grupo sem subluxação atlanto-axial e esclerose.

Em nossa avaliação não encontramos associação estatística significante da variável subluxação atlanto-axial com os valores da subluxação sub-axial e subluxação múltipla isoladamente. Para melhor se situar como já relatamos, a subluxação atlanto-axial associa-se com a migração superior do odontóide, mas não se correlaciona com as alterações subaxiais degenerativas da artrite reumatóide da coluna cervical (estreitamento discal cervical alto, esclerose da superfície vertebral e apófises articulares e osteoporose). Ao contrário, houve associação significante entre as variáveis subluxação subaxial única com estas alterações degenerativas descritas. A subluxação múltipla correlacionou-se com o estreitamento discal cervical alto e esclerose da superfície vertebral, ambas as subluxações não se associam com a migração superior do odontóide, o que nos sugere que as lesões da artrite reumatóide na coluna cervical inferior sejam mais tardias.

A osteoporose esteve presente em $67,9 \%$ de todos os pacientes portadores de artrite reumatóide. Provavelmente a maior 
freqüência de osteoporose esteja associada à evolução da doença e aos efeitos do uso prolongado de corticosteróides porém não podemos comprovar esse último dado sugerido por WINFIED et al. (1981), que correlacionam o uso de corticosteróide à gravidade da subluxação atlantoaxial, o qual induziria a frouxidão e ruptura do ligamento transverso e do ligamento alar, exercendo portanto, um efeito deletério ao nível de $C_{1}-C_{2}$.

CABOT \& BECKER (1978) relataram que todos os pacientes de seus estudos apresentaram evidência de osteoporose e WINFIELD et al. (1981) mostraram que a osteoporose estava presente em $41 \%$ dos pacientes portadores de subluxação atlanto-axial.

A artrite reumatóide afeta a coluna cervical muito freqüentemente, e apesar das alterações patológicas serem discretas e benignas para muitos pacientes, numa percentagem deles um padrão de instabilidade progressiva é desenvolvido (RANA, 1989; ODA et al., 1995), que pode comprometer as estruturas nervosas e vasculares adjacentes, cuja expressão clínica pode variar desde a mielopatia, incapacidade funcional, quadriplégia e até morte súbita (DREYER \& BODEN, 1999). Essas alterações da coluna cervical têm sido erroneamente consideradas lesões benignas e o tratamento cirúrgico reservado somente para os pacientes que apresentam déficit neurológico progressivo. Estudos recentes (BODEN et al., 1993; BODEN, 1994; PEPPELMAN et al., 1993) têm demonstrado que a estabilização precoce dos segmentos instáveis, mesmo na ausência de déficit neurológico, conduz a melhores resultados do ponto de vista da melhora do quadro neurológico e funcional (O'HARA et al., 1991; DREYER 
\& BODEN, 1999). Essa tendência atual de abordagem terapêutica é bastante direcionada ao número de pacientes que apresentam alterações da coluna cervical e pela ausência de sintomas específicos a elas relacionado, porém, acreditamos que esses pacientes em nosso meio não estão sendo monitorizados ou seguidos adequadamente. Portanto, serve para refletirmos acerca de nossa abordagem terapêutica com relação a essa doença.

Foi possível observar a presença de alterações radiográficas da coluna cervical em pacientes ambulatoriais, que embora evidentes ao estudo radiográfico, muitas vezes não apresentavam sequer dor cervical ou outros sinais clínicos. A associação dessas alterações com os estágios e classes da doença deve também ser considerada no acompanhamento dos pacientes, pois foi evidente o vínculo da gravidade da artrite reumatóide com o aumento das alterações da coluna cervical.

Esperamos que esse trabalho possa contribuir para 0 tratamento dos pacientes com artrite reumatóide, no sentido de alertar para a ocorrência de instabilidades importantes da coluna cervical, as quais poderiam evoluir para quadros de compressão grave das estruturas nervosas, pois apresentariam comportamento discreto nas fases iniciais, muitas vezes não acompanhados de sinais e sintomas clínicos, os quais foram anteriormente descritos. Somente a procura ativa dessas alterações permitirá o diagnóstico e tratamento adequados, antes que elas apresentem complicações funcionais ou neurológicas. 


\section{CONCLUSÕES}


Dos 81 pacientes ambulatoriais portadores de artrite reumatóide estudados, 65 (80,25\%) apresentaram alterações da coluna cervical e $22(27,16 \%)$ apresentaram instabilidade cervical (migração superior do odontóide, subluxação atianto-axial, subluxação subaxial e subluxação múltipla).

Não foi observado diferença significante entre a presença de alterações radiográficas de instabilidade cervical e a presença de cervicalgia e sinais neurológicos.

Foram observadas diferenças significantes entre as classes de evolução da doença (Classificação de Capacidade Funcional da Artrite Reumatóide e Classificação em Estágios da artrite reumatóide) e a presença de migração superior do odontóide.

O acometimento periférico articular da artrite reumatóide apresentou diferença significante em relação à gravidade do envolvimento da coluna cervical pela doença. 


\section{ANEXO A}

PROTOCOLO DE AVALIAÇÃO CLÍNICA E RADIOLÓGICA DOS PACIENTES PORTADORES DE ARTRITE REUMATÓIDE

1. NOME : $n^{2}$

Contato :

Reg: Raça :

Cor:

2. IDADE : 3. SEXO : 1 ( ) Masc.

2( ) Fem.

4. CLÍNICA

4.1. Início dos sintomas (duração)

4.2. Dor cervical

$$
\begin{aligned}
& 0 \text { ( ) ausente } \\
& 1(\text { ) leve } \\
& 2(\text { ) moderada } \\
& 3(\text { ) severa }
\end{aligned}
$$

4.3. Vertigem

1 ( ) Não 2 ( ) Sim

4.4. Tontura

1( ) Não 2 ( ) Sim

4.5. Cefaléia

1( ) Não 2( ) Sim

4.6. Distúrbios visuais

1 ( ) Não 2 ( ) Sim

4.7. Rigidez cervical

1( ) Não 2( ) Sim

4.8. Dor occiptal

1( ) Não 2 ( ) Sim

4.9. Espasmo tremor muscular

1 ( ) Não 2 ( ) Sim

4.10. Fraquesa muscula

1() Não 2() Sim

4.11. Incontinência urinária

1( ) Não 2 ( ) Sim

4.12. Adormecimento

1( ) Não 2 ( ) Sim

4.13. Perda do equilíbrio

1( ) Não 2 ( ) Sim

4.14. Sensação de crepitação

1 ( ) Não 2 ( ) Sim 
4.15. Sinais
4.15.1. Parestesia
1 ( ) Não 2 ( ) Sim
1 ( ) MMSS 2()

MMII

4.15.2. Reflexos $\quad 0($ ) normal $1($ ) aumentado $2($ )

diminuido
4.15.3. Babinsky
1( ) Não 2( ) Sim
4.15.4. Clonus
1 ( ) Não 2 ( ) Sim
4.15.5. Espasticidade
1( ) Não 2( ) Sim
5.15.6. Fraquesa muscular (objetiva)
1( ) Não 2( ) Sim

1() MMSS : $0($ ) leve 1() moderada 2()

severa

$$
\text { 2( ) MMII : } 0(\text { ) leve } 1(\text { ) moderada 2( ) }
$$

severa

5.15.7. Paresia

1( ) Não 2 ( ) Sim

4.16. Manifestação de Artrite em qualquer articulação periférica (AIP, MF, Punho, Cotovelo, Joelho, Tornozelo, Met-fal).

1 ( ) Não 2 ( ) Sim

4.17. Alterações clínicas nas mãos (Desvio ulnar, botoniere, pescoço de cisne)

1( ) Não 2( ) Sim

\section{DADOS LABORATORIAIS}

5.1. Soro positiva

- Látex

- Waaler-Rose

- Nefelometria

5.2. VHS

5.3. Proteínas C. Reativa

5.4. Mucoproteínas
1( ) Não 2( ) Sim

1 ( ) Não 2 ( ) Sim

1 ( ) Não 2 ( ) Sim

1 ( ) Não 2 ( ) Sim

1( ) Não 2( ) Sim

1 ( ) Não 2 ( ) Sim

1 ( ) Não 2 ( ) Sim 


\section{QUANTO À AVALIAÇÃO CLÍNICA}

6.1. Critérios revisados da ACR - Critérios Diagnóstico de AR revisados pelo American College of Rheumatology

6.1.1. Rigidez matinal com duração de pelo menos 1 hora 1 ( ) Não 2( ) Sim

6.1.2. Artrite observada pelo médico em 3 ou mais articulações, das 14 seguintes áreas: interfalangeanas proximais (IFP), metacarpofalangianas (MCF), punhos, cotovelos, joelhos, tornozelos e metatarsofalangianas (MTF). Cada lado (direito ou esquerdo) é considerado uma área.

$$
\text { 1( ) Não 2( ) Sim }
$$

6.1.3. Artrite observada pelo médico pelo menos 1 das articulações das mãos, ou seja, punhos, MCF e IFP.

$$
\text { 1( ) Não 2( ) Sim }
$$

6.1.4. Artrite simétrica. Acometimento simultâneo da mesma articulação em ambos os lados do corpo. $O$ acometimento das MCE, IFP e MTF é aceitável sem absoluta simetria.

$$
\text { 1( ) Não 2( ) Sim }
$$

6.1.5. Nódulos subcutâneos observados pelo médico

$$
\text { 1( ) Não 2( ) Sim }
$$

6.1.6. Presença de títulos anormais de fator reumatóide

$$
\text { 1( ) Não } 2 \text { ( ) Sim }
$$

6.1.7. Alterações radiográficas características da $A R$, incluindo osteoporose periarticular e as erosões características

$$
\text { 1( ) Não 2( ) Sim }
$$

Pode se dizer que o paciente tenha AR caso apresente ao menos 4 desses 7 critérios. Os critérios de número 1 a 4 devem estar presentes pelo menos durante 6 semanas.

6.2. Classificação de Capacidade Funcional

\subsubsection{I ( ) Completa habilidade para realizar todos os deveres sem embaraço.}


6.2.2. II ( ) Adequada para atividades normais - apesar de embaraço ou dificuldade ou movimentos limitados em uma ou mais articulações

6.2.3. III ( ) Limitada - somente poucos deveres da ocupação usual ou cuidados próprios.

6.2.4. IV ( ) Incapacidade, total ou grande - preso à cama ou cadeira de rodas, nenhum cuidado pessoal.

6.3. Classificação dos Estágios da AR ( ARA )

(Steinbrocker, Jama, vol. 140, n 8, 1949, pg. 659-662).

6.3.1. ( ) Estágio I, precoce

1. Sem alterações destrutivas radiológica

2. Evidência radiológica de osteoporose pode estar presente

6.3.2. ( ) Estágio II, moderado

1. Evidência radiológica de osteoporose, com ou sem, leve destruição óssea subcondrial; leve destruição da cartilagem pode estar presente.

2. Nenhuma deformidade articular, entretanto limitação da mobilidade articular pode estar presente.

3. Atrofia muscular adjacente

4. Lesão de tecidos moles extra-articular, tais como módulos e tenovaginites, pode estar presentes.

\subsection{3. ( ) Estágio III, grave}

1. Evidência radiológica de destruição óssea e cartilagem, somada a osteoporose

2. Deformidade articular, como subluxação, desvio ulnar ou hiperextensão, sem fibrose ou anquilose óssea.

3. Extensa atrofia muscular.

4. Lesão de tecidos moles extraarticular, como nódulos e tenovaginites. 


\subsection{4. ( ) Estágio IV, terminal \\ 1. Fibrose ou anquilose óssea \\ 2. Critérios de estágios III}

\section{CRITÉRIOS DE AVALIAÇÃO RADIOGRÁFICA}

- A ampola de RX deve estar a 1,5m de chassi, para a realização da radiografia como o feixe de luz centrado em $\mathrm{C} 2$.

- Realização da radiografia da coluna cervical em perfil (flexão, extensão

e neutro) e frente.

- Realização da radiografia das mãos $(F+O)$, necessário a classificação do estágio.

- Critérios para a TAC:

- Dificuldade de visualização para traçar a linha de MacGregor.

- Casos suspeitos de invaginação basilar.

- Pacientes com mielopatia severa.

- Achados clínicos não explicados pelo exame de RX.

- Critérios para a avaliação da radiografia

- vo-valor obtido

- Subluxação vertical

Linha de Ranawat

valor normal : H. $\cdot 15 \mathrm{~mm}$

M. $\cdot 13 \mathrm{~mm}$

$\mathrm{VO}=$

1( ) não 2( ) sim

Linha de Redlund-Johnell

valor normal :

H. $\cdot 34 \mathrm{~mm}$

M. $\cdot 29 \mathrm{~mm}$

VO =

1( ) não 2 ( ) sim 
Linha de MacGregor

valor normal : $<4,5$

$$
\begin{aligned}
& \text { VO }= \\
& 1(\text { ) não } \quad 2() \operatorname{sim}
\end{aligned}
$$

Instabilidade atlanto-axial (C1-C2) - subluxação > 3mm

$$
\begin{aligned}
& \text { VO }= \\
& 1(\text { ) não } \quad 2() \operatorname{sim}
\end{aligned}
$$

Instabilidade C3-C7 - critério de White-Panjabi - quando há presença de angulação • $\|^{\circ}$ e ou subluxação • 3,5 mm

$$
\begin{aligned}
& \text { VO }= \\
& 1(\text { ) não } \quad 2() \operatorname{sim}
\end{aligned}
$$

\section{8- DEMAIS POSSÍVEIS LESÕES}

8.1. Erosão do odontóide 1 ( ) não $2($ ) sim

8.2. Estreitamentodiscal afetando os discos da coluna cervical alta sem osteofitos

1 ( ) não 2( ) sim

8.3. Subluxação múltipla de $1 \mathrm{~mm}$ ou mais

1 ( ) não 2 ( ) sim

8.4. Esclerose e erosão da superfície vertebral

1( ) não 2 ( ) sim

8.5. Esclerose e erosão da apófise articulares

1 ( ) não 2( ) sim

8.6. Osteoporose

1 ( ) não 2.( ) sim

8.7. Fusão óssea

1( ) não 2( ) sim 


\section{ANEXO B}

\section{VALORES DAS ASSOCIAÇÕES ENTRE AS VARIÁVEIS ESTUDADAS}

\begin{tabular}{|c|c|c|c|}
\hline \multirow[b]{2}{*}{ Variáveis estudadas } & \multicolumn{2}{|c|}{ Método } & \multirow[b]{2}{*}{$\begin{array}{c}\text { Subluxação } \\
\mathrm{C}_{1}-\mathrm{C}_{2}\end{array}$} \\
\hline & Ranawat & $\begin{array}{l}\text { Redlund- } \\
\text { Johnell }\end{array}$ & \\
\hline Cervicalgia & 0.610 & 0.718 & 0.331 \\
\hline Verti & 0.349 & 0.178 & 1 \\
\hline Tontura & 0.498 & 0.058 & 0.748 \\
\hline Cefaléia & 0.0 & 0.044 & 0.733 \\
\hline Distúrbios visuais & 0.501 & 0.593 & 1 \\
\hline Rigidez cervical & 56 & 0.623 & 0.125 \\
\hline Dor c & 0.731 & 0.262 & 0.302 \\
\hline unscular & 0.673 & 0.249 & 0.077 \\
\hline lar subjetiva & 0.2 & 0.596 & 0.499 \\
\hline inária & & 0.864 & 1 \\
\hline dos membros & 0.7 & 0.234 & 0.734 \\
\hline Perda do $\Theta$ & 0.070 & 0.380 & 0.033 \\
\hline Sens & 0.004 & 0.088 & 0.277 \\
\hline Pare & 0. & 0.460 & 0.038 \\
\hline Alter & 0.0006 & 0.041 & 0.086 \\
\hline Babinsky & 1 & 1 & 1 \\
\hline & 0.092 & 0.527 & 0.112 \\
\hline nidedo & 0. & 0.862 & 1 \\
\hline Pare & 1 & 0.745 & 0.851 \\
\hline Fra & 0.022 & 0.200 & 0.217 \\
\hline férica & 1 & 1 & 1 \\
\hline clínica da mão & 0.104 & 0.030 & 0.054 \\
\hline Soro $\mathrm{pc}$ & 0.518 & 0.404 & 1 \\
\hline Late & & 0.293 & 1 \\
\hline Waaler-Rose & 0.472 & 0.670 & 0.194 \\
\hline VHS & 0.788 & 0.745 & 1 \\
\hline PCR & 0.481 & 0.404 & 1 \\
\hline Mucoproteína & 0.423 & 0.344 & 0.588 \\
\hline & 0.788 & 0.745 & 1 \\
\hline ou mais articulaçōes & $: 1$ & $\therefore 1$ & 1 \\
\hline Artrite & 1 & $i$ & 1 \\
\hline Artrite & 1 & 1 & $1 \ldots$ \\
\hline Nódulo & 0.372 & 0.293 & 0.255 \\
\hline & 0.627 & 0.293 & 1 \\
\hline adiográficas características da $A R$ & 0.102 & 0.058 & 0.040 \\
\hline Classificação de capacidade funcional & 0.00001 & 0.013 & 0.197 \\
\hline Classificação em estágios da AR & 0.014 & 0.025 & 0.007 \\
\hline
\end{tabular}




\begin{tabular}{|c|c|c|c|}
\hline Variáveis estudadas & $\begin{array}{c}\text { Subluxação } \\
\text { subaxial } \\
C_{2}-C_{7}\end{array}$ & $\begin{array}{c}\text { Estreitament } \\
0 \\
\text { Discal } \\
\text { Cervical Alto }\end{array}$ & $\begin{array}{l}\text { Erosāo do } \\
\text { Odontóide }\end{array}$ \\
\hline Cervicalgia & 0.417 & 0.256 & 0.817 \\
\hline $\mathrm{Ve}$ & 172 & 0.248 & 0.392 \\
\hline Tontura & 0.238 & 0.373 & 0.355 \\
\hline Cefaléia & 0.361 & 0.010 & 0.159 \\
\hline Distúrbios visuais & 0.257 & 0.5003 & 0.816 \\
\hline Rigide & 0.120 & 0.619 & 1 \\
\hline & 73 & 0.357 & 0.640 \\
\hline uscular & & 0.203 & \\
\hline Ir subjetiva & 0 & 0.5 & 5 \\
\hline Inco & 0.5 & 0. & \\
\hline membros & 0.6 & 0.651 & \\
\hline quillbri & 0.060 & 0.243 & 0.055 \\
\hline de crepitação & 0.185 & 0.813 & 5 \\
\hline Pare & 7 & 0.420 & 0.785 \\
\hline s dos reflexos & 0.2 & 0.034 & 0.349 \\
\hline Bab & 1 & 1 & 1 \\
\hline Clor & 0.028 & 0.326 & 0.592 \\
\hline ticidade & 0.95 & 0.6 & 0.65 \\
\hline Pare & 08 & 0.162 & 0 \\
\hline Fraq & 0.307 & 0.179 & 0.785 \\
\hline iférica & 1 & 1 & 1 \\
\hline clínica da mão & 0.195 & 0.037 & 0.067 \\
\hline Soro positiva & 0.673 & 0.211 & 0.062 \\
\hline Latex & 0.413 & 0.288 & 0.144 \\
\hline Waaler-Rose & 0.348 & 0.574 & 0.082 \\
\hline VHS & 0.879 & 0.651 & 0.409 \\
\hline PCR & 0.673 & 0.471 & 0.294 \\
\hline Mi & 0.628 & 0.397 & 0.511 \\
\hline Rigidez matinal & 0.879 & 0.651 & 0.590 \\
\hline Artrite em 3 ou $n$ & 1 & 1 & 1 \\
\hline Artrit & 1 & 1 & 1 \\
\hline Artrit & 1 & 1 & 1 \\
\hline Nódulo sub-cutânea & 0.586 & 0.173 & 0.103 \\
\hline & 0.413 & 0.087 & 0.400 \\
\hline Alterações radiográficas caracteristicas da AR & 0.213 & 0.076 & 0.070 \\
\hline oacidade funcional & 0.027 & 0.0054 & 0.205 \\
\hline Classificação em estágios da AR & 0.025 & 0.0001 & 0.0005 \\
\hline
\end{tabular}




\begin{tabular}{|c|c|c|c|}
\hline Variáveis estudadas & $\begin{array}{c}\text { Subluxação } \\
\text { Múltipla }\end{array}$ & $\begin{array}{c}\text { Osteopor } \\
\text { ose }\end{array}$ & Fusão Óssea \\
\hline Cervicalgia & 0.326 & 0.346 & 1 \\
\hline Vertigem & 0.448 & 0.495 & 0.538 \\
\hline Tontura & 0.376 & 0.638 & 0.213 \\
\hline Cefaléia & 0.138 & 0.150 & 0.125 \\
\hline Distúrbios visuais & 0.228 & 0.2419 & 0.403 \\
\hline Rigidez cervical & 0.299 & 0.150 & 0.007 \\
\hline Dor occipital & 0.539 & 0.477 & 0.488 \\
\hline Espasmo muscular & 0.618 & 0.601 & 0.249 \\
\hline Fraqueza muscular subjetiva & 0.089 & 0.338 & 0.183 \\
\hline Incontinéncia urinária & 0.95 & 0.679 & 0.864 \\
\hline Adormecimento dos membros & 0.438 & 1 & 0.525 \\
\hline Perda do equilfbrio & 0.474 & 0.0012 & 0.053 \\
\hline Sensação de crepitação & 0.385 & 0.618 & 0.245 \\
\hline Parestesia & 0.212 & 0.043 & 0.060 \\
\hline Alterações dos reflexos & 0.116 & 0.0004 & 0.0008 \\
\hline Babinsky & 1 & 1 & 1 \\
\hline Clonus & 0.228 & 0.135 & 0.133 \\
\hline Espasticidade & 0.950 & 0.675 & 0.875 \\
\hline Paresia & 0.903 & 0.541 & 0.254 \\
\hline Fraqueza muscular objetiva & 0.212 & 0.043 & 0.012 \\
\hline Manifestação de artrite periférica & 1 & 1 & 1 \\
\hline Deformidade clínica da mão & 0.273 & 0.014 & 0.137 \\
\hline Soro positiva & 0.269 & 0.631 & 0.404 \\
\hline Latex & 0.654 & 0.505 & 0.293 \\
\hline Waaler-Rose & 0.154 & 0.432 & 0.67 \\
\hline VHS & 0.903 & 0.100 & 0.745 \\
\hline PCR & 0.269 & 0.631 & 0.404 \\
\hline Mucoproteína & 0.691 & 0.399 & 0.655 \\
\hline Rigidez matinal & 0.903 & 0.541 & 0.745 \\
\hline Artrite em 3 ou mais articulações & 1 & 1 & 1 \\
\hline Artrite em mãos & 1 & 1 & 1 \\
\hline Artrite simétrica & 1 & 1 & 1 \\
\hline Nódulo sub-cutânea & 0.654 & 0.494 & 0.296 \\
\hline Título anormal de FR & 0.654 & 0.505 & 0.703 \\
\hline Alteraçōes radiográficas características da AR & 0.293 & 0.0002 & 0.158 \\
\hline Classificação de capacidade funcional & 0.012 & 0.052 & 0.013 \\
\hline Classificação em estágios da AR & 0.054 & 0.0001 & 0.025 \\
\hline
\end{tabular}




\section{MÉTODO DE RANAWAT}

\begin{tabular}{lr}
\hline \hline Variáveis estudadas & Valor de p \\
\hline Redlund-Johnell & 0.0001 \\
Subluxação atlantoaxial $C_{1}-C_{2}$ & 0.011 \\
Subluxação subaxial $C_{2}-C_{7}$ & 0.09 \\
Erosão do odontóide & 0.062 \\
Estreitamento cervical discal alto & 0.094 \\
Subluxação múltipla & 0.059 \\
Esclerose superfície vertebral & 0.072 \\
Esclerose das apófises articulares & 0.038 \\
Osteoporose & 0.051 \\
Fusão óssea & 0.017 \\
\hline
\end{tabular}

\section{MÉTODO REDLUND-JOHNELL \& PETTERSSON}

\begin{tabular}{lr}
\hline Variáveis estudadas & Valor de p \\
\hline Ranawat & 0.0001 \\
Subluxação atlantoaxial $C_{1}-C_{2}$ & 0.0032 \\
Subluxação subaxial $C_{2}-C_{7}$ & 0.133 \\
Erosão do odontóide & 0.048 \\
Estreitamento cervical discal alto & 0.043 \\
Subluxação múltipla & 0.086 \\
Esclerose superficie certebral & 0.1004 \\
Esclerose das apófises articulares & 0.056 \\
Osteoporose & 0.072 \\
Fusão óssea & 0.166 \\
\hline
\end{tabular}




\section{SUBLUXAÇÃO ATLANTOAXIAL $\mathrm{C}_{1}-\mathrm{C}_{2}$}

\begin{tabular}{lr}
\hline Variáveis estudadas & Valor de p \\
\hline Ranawat & 0.011 \\
Redlund-Johnell & 0.003 \\
Subluxação subaxial $C_{2}-C_{7}$ & 0.112 \\
Erosão do odontóide & 0.031 \\
Estreitamento cervical discal alto & 0.163 \\
Subluxação múltipla & 0.415 \\
Esclerose superfície vertebral & 0.517 \\
Esclerose das apófises articulares & 0.103 \\
Osteoporose & 0.103 \\
Fusão óssea & 0.026 \\
\hline
\end{tabular}

\section{SUBLUXAÇÃO SUBAXIAL $C_{2}-C_{7}$}

\begin{tabular}{lr}
\hline Variáveis estudadas & Valor de p \\
\hline Ranawat & 0.092 \\
Subluxação atlantoaxial $C_{1}-C_{2}$ & 0.112 \\
Redlund-Johnell & 0.133 \\
Erosão do odontóide & 0.052 \\
Estreitamento cervical discal alto & 0.0092 \\
Subluxação múltipla & 0.017 \\
Esclerose superfície vertebral & 0.017 \\
Esclerose das apófises articulares & 0.047 \\
Osteoporose & 0.135 \\
Fusão óssea & 0.0164 \\
\hline
\end{tabular}




\section{EROSÃO DO ODONTÓIDE}

\begin{tabular}{lr}
\hline Variáveis estudadas & Valor de p \\
\hline Ranawat & 0.049 \\
Subluxação atlantoaxial $C_{1}-C_{2}$ & 0.030 \\
Redlund-Johnell & 0.043 \\
Subluxação subaxial $C_{2}-C_{7}$ & 0.052 \\
Estreitamento cervical discal alto & 0.0048 \\
Subluxação múltipla & 0.452 \\
Esclerose superfície vertebral & 0.0024 \\
Esclerose das apófises articulares & 0.0004 \\
Osteoporose & 0.137 \\
Fusão óssea & 0.013
\end{tabular}

\section{SUBLUXAÇÃO MÚLTIPLA}

\begin{tabular}{lr}
\hline Variáveis estudadas & Valor de p \\
\hline Ranawat & 0.059 \\
Subluxação atlantoaxial $C_{1}-C_{2}$ & 0.415 \\
Redlund-Johnell & 0.086 \\
Subluxação subaxial $C_{2}-C_{7}$ & 0.017 \\
Estreitamento cervical discal alto & 0.024 \\
Erosão odontóide & 0.452 \\
Esclerose superfície vertebral & 0.039 \\
Esclerose das apófises articulares & 0.089 \\
Osteoporose & 0.204 \\
Fusão óssea & 0.448
\end{tabular}




\section{ESTREITAMENTO DISCAL CERVICAL ALTO}

\begin{tabular}{lr}
\hline Variáveis estudadas & Valor de p \\
\hline Ranawat & 0.094 \\
Subluxação atlantoaxial $C_{1}-C_{2}$ & 0.302 \\
Redlund-Johnell & 0.043 \\
Subluxação subaxial $C_{2}-C_{7}$ & 0.009 \\
Subluxação múltipla & 0.024 \\
Erosão do odontóide & 0.0048 \\
Esclerose superfície vertebral & 0.0001 \\
Esclerose das apófises articulares & 0.0001 \\
Osteoporose & 0.0016 \\
Fusão óssea & 0.00038 \\
\hline
\end{tabular}

\section{OSTEOPOROSE}

Variáveis estudadas

Ranawat

Subluxação atlantoaxial $\mathrm{C}_{1}-\mathrm{C}_{2}$

Redlund-Johnell

Subluxação subaxial $\mathrm{C}_{2}-\mathrm{C}_{7}$

Subluxação múltipla

Erosão do odontóide

Esclerose superfície vertebral

Esclerose das apófises articulares

Estreitamento discal cervical alto

Fusão óssea
Valor de $p$

0.024

0.155

0.072

0.135

0.024

0.137

0.0003

0.0001

0.0016

0.0098 


\section{FUSÃO ÓSSEA}

\begin{tabular}{lr}
\hline Variáveis estudadas & Valor de p \\
\hline Ranawat & 0.017 \\
Subluxação atlantoaxial $\mathrm{C}_{1}-\mathrm{C}_{2}$ & 0.026 \\
Redlund-Johnell & 0.166 \\
Subluxação subaxial $\mathrm{C}_{2}-\mathrm{C}_{7}$ & 0.016 \\
Subluxação múltipla & 0.448 \\
Erosão do odontóide & 0.013 \\
Esclerose superfície vertebral & 0.0001 \\
Esclerose das apófises articulares & 0.0008 \\
Estreitamento discal cervical alto & 0.0003 \\
Osteoporose & 0.013 \\
\hline
\end{tabular}

\section{ESCLEROSE DA SUPERFÍCIE VERTEBRAL}

\begin{tabular}{lr}
\hline Variáveis estudadas & Valor de p \\
\hline Ranawat & 0.044 \\
Subluxação atlantoaxial $C_{1}-C_{2}$ & 1 \\
Redlund-Johnell & 0.1004 \\
Subluxação subaxial $C_{2}-C_{7}$ & 0.017 \\
Subluxação múltipla & 0.039 \\
Erosão do odontóide & 0.0024 \\
Fusão óssea & 0.0001 \\
Esclerose das apófises articulares & 0.0001 \\
Estreitamento discal cervical alto & 0.0001 \\
Osteoporose & 0.0003 \\
\hline
\end{tabular}




\section{ESCLEROSE DAS APÓFISES ARTICULARES}

\begin{tabular}{lr}
\hline Variáveis estudadas & Valor de p \\
\hline Ranawat & 0.033 \\
Subluxação atlantoaxial $C_{1}-C_{2}$ & 1 \\
Redlund-Johnell & 0.056 \\
Subluxação subaxial $C_{2}-C_{7}$ & 0.047 \\
Subluxação múltipla & 0.089 \\
Erosão do odontóide & 0.0004 \\
Esclerose da superfície vertebral & 0.0001 \\
Fusão óssea & 0.0008 \\
Estreitamento discal cervical alto & 0.0001 \\
Osteoporose & 0.0001 \\
\hline
\end{tabular}




\section{REFERÊNCIA BIBLIOGRÁFICA}


Albert, D. Rachis cervical rhumatoide et potentiels evoques somentesiques dynamiques. Bordeaux, 1995. p.99, These (Docteur), Universite de Bourdeaux II U.F.R. des Sciences Medicales.

Arnett, F.C.; Edworthy, S.M.; Bloch, D.A.; The American Rheumatism Association 1987. Revised criteria for the Classification of Rheumatoid Arthritis. Arthritis Rheum., v.31, n.3, p.315-24, 1988.

Ball, J. \& Sharp, J., ed. - Rheumatoid arthritis of the cervical spine. In: Hill, A.G.S. Modern trends rheumatology. London, Butterwarth, 1971, p.117-38.

Barros Filho, T.E.P.; Carneiro, J.F.; Hasegawa, O.H.; Leivas T.P. Parâmetros para avaliação das radiográfias da transição occipitocervical. Rev. Bras. Ortop., v.25, n.3, p.75-8, 1990.

Barros Filho, T.E.P.; Oliveira, R.P.; Rodrigues, N.R.; Greve, J.M.D.; Laurindo, I.M.M.; Pereira, R.M.R.; Cossermelli, W. Alteraçōes radiográficas da coluna cervical na artrite reumatóide. Rev. Bras. Ortop., v.27, n.5, p.344-51, 1992.

Barros Filho, T.E.P.; Oliveira, R.P.; Taricco, M.A. A artrite reumatóide e a coluna cervical. Rev. Bras. Ortop., v.24, n.10, p.361-64, 1989.

Boden, S.D. Rheumatoid arthritis of the cervical spine. Spine, v.19, n.20, p.227580, 1994.

Boden, S.D.; Dodge, L.D.; Bohlman, H.H.; Rechtine, G.R. Rheumatoid arthritis of the cervical spine. J.Bone Joint Surg., v.75A, n.9, p.1282-97, 1993.

Braunstein, E.M.; Weissman, B.N.; Seltzer, S.E.; Sosman, J.L.; Wang, A.; Zamani, A. Computed tomography and conventional radiographs of the cranio cervical region in rheumatoid arthritis. Arthritis and Rheum., v. 27, n.1, p.26-31, 1984.

Breedveld, F.C.; Algra, P.R.; Vielvoye, C.J.; Cats, A. Magnetic resonance imaging in the evaluation of patients with rheumatoid arthritis and subluxations of the cervical spine. Arthritis and Rheum., v.30, n.6, p.624-9, 1987.

Cabot, A. \& Becker, A. The cervical spine in rheumatoid arthritis. Clin. Orthop., v.131, p.130-40, 1978.

Collins, D.N.; Barnes, C.L.; FitzRandolf, R.L. Cervical spine instability in rheumatoid patients having total hip or knee antroplasty. Clin. Orthop., v.272, p.127-35, 1991.

Conlon, P.W.; Isdale, I.C.; Rose, B.S. Rheumatoid arthritis of the cervical spine: an analysis of 333 cases. Ann. Rheum. Dis., v.25, n.2, p.120-25, 1966.

Crockard, H.A. Spine update surgical management of rheumatoid problems. Spine, v.20, n.23, p.2584-90, 1995.

Davis, F.W. \& Markley, H.E. Rheumatoid arthritis with death from medullary compression. Ann. Med., v.35, n.2, p.451-4, 1951. 
Delamarter, R.B. \& Bohlman H.H. Postmorten osseus and neuropathology analysis of the rheumatoid cervical spine. Spine, v.19, n.20, p.2267-74, 1994.

Dreyer, S.J. \& Boden, S.D. Natural history of rheumatoid arthritis of the cervical spine. Clin. Orthop. n.366, p.98-106, 1999.

Dvorak, J.; Grob, D.; Baumgartner, H.; Gschwend, N.; Graver W.; Larson, S. Functional evaluation of the spinal cord by magnetic resonance imaging in patients with rheumatoid arthritis and instability of upper cervical spine. Spine, v.14, n.10, p.1057-64, 1989.

Eulderink, F. \& Meijers, K.A.E. Pathology of the cervical spine in rheumatoid arthrits: a controled study of 44 spines. J. Path., v.120, n.2, p.91-108, 1976.

Fehring, T.K. \& Brooks, A.L. Upper cervical instability in rheumatoid arthritis. Clin. Orthop., n.221, p.137-48, 1987.

Floyd, A.S. Learmonth, I.D.: Mody, G.; Meyers, D.L. Atlanto-axial instability and neurologic indicators in rheumatod arthritis. Clin. Orthop., n.241, p.177-82, 1989.

Garrod, A.E. A treatise on rheumatism and rheumatoid arthritis. London, Grifin, 1890, p.1-342.

Grob, D. Principies of surgical treatment of the cervical spine in rheumatoid arthritis. Eur. Spine J., n.2, p.180-90, 1993.

Grob, M.D.; Wusch, R.; Grauer, W.; Sturzenegger, J.; Dvorak, J. Atlantoaxial fusion and retrodental pannus in rheumatoid arthritis. Spine, v.22, n.14, p.1580-83, 1997.

Hochberg, M.C.; Chane, R.W.; Dwash, I.; Lindsey. S.; Pincus, T.; wolfe, F. The American College of Rheumatology 1991, resided criteria for the classification of global funcional status in rheumatoid arthritis. Arthritis Rheum, v.35, n.5, p.498502, 1992.

Kawaida, H.; Sakou, T.; Morizono Y. Vertical settling in rheumatoid arthritis. Clin. Orthop., n.239, p.128-35, 1989.

Kawaida, H.; Sakou, T.; Morizono, Y.; Yoshikuni, N. Magnetic resonance imaging of upper cervical disorders in rheumatoid arthritis. Spine, v.14, n.11, p.1144-8, 1989.

Kramer, J.; Jolesz, F.; Kleefield J. Rheumatoid arthritis of the cervical spine. Rheum. Dis. Clin. North Am. v.17, n.3, p.757-73, 1991.

Lipson S.J. Cervical mielopathy and posterior atlanto-axial subluxation in patients with rheumatoid arthritis. J Bone Joint Surg., v.67A, n.4, p.593-7, 1985.

Lipson S.J. Rheumatoid arthritis of the cervical spine. Clin. Orthop., n.182, p.143-9, 1984. 
Lipson, S.J. Rheumatoid arthrits of the cervical spine. Clin. Orthop., n.239, p.127-7, 1989.

MacGregor, M. The significance of certain measurements of the skull in the diagnosis of basilar impression. Br. J. Radiol., n.21, p.171-81, 1948.

Martel, W. Pathogenesis of cervical discovertebral destruction in rheumatoid arthritis. Arthritis Rheum., v.20, n.6, p.1217-25, 1977.

Mathews,J.A. Atlanto-axial subluxation in rheumatoid arthritis. Ann. Rheum. Dis., v.28, n.3, p.260-6, 1969.

Meijers, K.A.E.; vanBeusekom, G.T.; Lueyendijk, W.; Duijfjes, F. Dislocation of the cervical spine with cord compression in rheumatoid arthritis. J. Bone Joint Surg., v.56B, n.4, p.668-80, 1974.

Meikle, J. \& Wilkson, M. Rheumatoid involvement of the cervical spine. Ann. Rheum. Dis., v.30. n.2, p.154-61, 1971.

Menezes, A.H.;Van Gilder, J.C.; Clark, C.R.; el-Khoury, G. Odontoid upward migration in Rheumatoid arthritis. J. Neurosurg., v.63, n.4, p.500-9, 1985.

Mikulowski, P.; Wollheim, F.A.; Rotmil, P.; Olsen, I. Sudden death in rheumatoid arthritis with atlanto-axial dislocation. Acta Med. Scandinavica, v.198, n.6, p.445-51, 1975.

Morizono, Y.; Sakou, T.; Kawaida, H. Upper cervical involvement in rheumatoid arthritis. Spine, v.12. n.8, p.72-6, 1987.

O'hara, R.; Silvaggio, V.; Donaldson, W.F.; Kraus, D.R. Surgery for rheumatoid arthritis of the cervical spine. In: Bridwell, K.H. \& De Wald, R.L., (2 ed.) The textbook of spinal surgery. Philadelphia, J.B. Lippincott Company, 1991. p.1439.

Oda, T.; Fujiwara, K.; Azuma B.; Ochi, T. Natural course of cervical spine lesions in rheumatoid arthritis. Spine, v.20, n.15, p.1128-35, 1995.

Pellici, P.M.; Ranawat, C.S.; Tsairis, P.; Bryan, W.J. A prospective study of the progression of rheumatoid arthritis of the cervical spine. J. Bone Joint. Surg., v.63A, n.3, p.342-50, 1981.

Peppelman, W.C.; Kraus, D.R.; Donaldson, W.F.; Agarwal, A. Cervical spine surgery in rheumatoid arthrits: improvement of neurologic deficit after cervical spine fusion. Spine, v.18, n.16, p.2375-9, 1993.

Rana, A.N. Natural history of atlanto-axial subluxation in rheumatoid arthritis. Spine, v.14, n.10, p.104-6, 1989.

Ranawat, C.S.; O'Leary, P.; Pellici, P.; Tsairis, P.; Marchisello, P.; Dorr, L. Cervical spine fusion in rheumatoid arthritis. J. Bone Joint Surg., v.61A, n.7, p.1003-10, 1979. 
Rana, A.N. Natural history of atlanto-axial subluxation in rheumatoid arthritis. Spine, v.14, n.10, p.104-6, 1989.

Ranawat, C.S.; O'Leary, P.; Pellici, P.; Tsairis, P.; Marchisello, P.; Dorr, L. Cervical spine fusion in rheumatoid arthritis. J. Bone Joint Surg., v.61A, n.7, p.1003-10, 1979.

Redlund-Johnell, I. \& Petterson, H. Radiografic measurements of the craniovertebral region. Acta Radiol. Diagn., v.25, n.1, p.23-8, 1984.

Sharp, J.; Pulser, J.; Lawrence, J. Rheumatoid arthritis of the cervical spine in adults. Ann. Rheum. Dis., v.17, p.303-13, 1958.

Smith, P.H.; Benn, R.T.; Sharp, J. Natural history of rheumatoid cervical subluxation. Ann. Rheumat., v.31, n.6, p.431-9, 1972.

Steinbrocker, O.; Traeger, C.H.; Batterman, R.C. Therapeutic criteria in rheumatoid arthritis. JAMA, v.140, n.8, p.659-62, 1949.

Stevens, J.M.; Kendall, B.E.; Crockard, H.A. The spinal cord in rheumatoid arthritis with clinical myelopathy: a computed myelografic study. J.Neurol. Neurosurg. Psychiatry, v.49, n.2, p.140-51, 1986.

Toolanen, G.; Larsson, S.E.; Fagerlund, M. Medullary compression in rheumathoid atlanto-axial subluxation evaluated by computerized tomography. Spine, v.11, n.3, p.191-4, 1986.

Weissman, B.N.W.; Aliabadi, P.; Weinfeld, M.S.; Thomas, W.H.; Sosman, J.L. Prognostic features of atlanto-axial subluxation in rheumathoid arthritis. Radiology, v.144, n.4, p.745-51, 1982.

White, A.A. \& Panjabi, M.M. Update on the evolution of the instability of the lower cervical spine . Instr. Course Lect., v.32, p.513-20, 1987.

Winfield, J.; Cooke, D.; Brook, A. S.; Corbett, M. A propesctive study of the radiological changes in the cervical spine in early rheumatoid disease. Ann. Rheum. Dis., v.40, n.2, p.109-14, 1981.

Yaszemski, M.J. \& Shepler, T.R. Sudden death from cord compression associated with atlanto-axial instabiliy in rheumatoid arthritis. Spine, v.15, n.4, p.338-41, 1990.

Zeidman, S.M. \& Ducker, T.B. Rheumatoid arthritis neuroanathomy, compression, and grading. Spine, v.19, n.20, p.2259-66, 1994. 


\section{SUMMARY}

During the period from February 1994 to July 1996, a study was conducted on 81 patients with rheumatoid arthritis followed up at the immunology outpatient clinic of the University Hospital, Faculty of Medicine of Ribeirão Preto. The objective of the study was to determine the presence of changes in the cervical spine of these patients and their association with clinical signs and symptoms, to obtain laboratory data and to classify the disease according to stage as recommended by the American Rheumatism Association (ARA) and class as recommended by the American College of Rheumatology (ACR).

Atlantoaxial subluxation, odontoid upward migration, subaxial and multiple subluxation, odontoid erosion, upper cervical disk narrowing, sclerosis of the vertebral and articular surface, osteoporosis and bone fusion were the radiographic parameters selected for the study of cervical spine changes in these patients.

Association between the parameters was calculated by the chi-square test, and Fisher's exact test, with the level of significance set at $p<0.05$.

Atlantoaxial subluxation was observed in 10 patients, upper odontoid migration in 13 , odontoid erosion in 29 , subaxial subluxation in 5 , upper cervical disk narrowing in 33 , multiple subluxation in 4 , sclerosis of the 
vertebral surface in 37 , sclerosis of the articular apophyses in 45, osteoporosis in 55, and bone fusion in 11.

Significant associations were observed between the parameter of the Ranawat method and headache, crepitation sensation, altered reflexes, objective muscle weakness, classification of functional status, Redlund-Johnell method, atlantoaxial subluxation, odontoid erosion, sclerosis of the vertebral surface, sclerosis of the vertebral and articular apophysis, and bone fusion.

The parameters that presented significant differences by the method of Redlundy-Johnell were: headache, altered reflexes, clinical deformity of the hands, classification of functional status, classification into ACR stages, atlantoaxial subluxation, odontoid erosion, and upper cervical disk narrowing.

Atlantoaxial subluxation was significantly associated with the following parameters: loss of equilibrium, parestesia, classification into ACR stages, odontoid erosion, and bone fusion.

Subaxial subluxation was significantly associated with the following parameters: clonus, classification of functional status, classification into ACR stages, upper cervical disk narrowing, multiple subluxation, sclerosis of the vertebral surface, and esclerosis of articular apophyses bone fusion. 
Multiple subluxation was significantly associated with the following parameters: classification of functional status, upper cervical disk narrowing, and sclerosis of the vertebral surface.

Odontoid erosion, upper cervical disk narrowing, bone fusion, and sclerosis of articular and vertebral apophyses were associated with each other.

The alterations of rheumatoid arthritis are associated with progression of the disease. We observed the development of instability of the vertebral spine in asymptomatic patients or patients with minimal neurologic findings, indicating that the presence of radiographic signs of instability is not necessarily associated with the neurologic picture. 